\title{
Runoff and Sediment Response to Cascade Hydropower Exploitation in the Middle and Lower Han River, China
}

\author{
Junhong Zhang, ${ }^{1,2}$ Mingkun Sun, ${ }^{1,2}$ Zhimin Deng, ${ }^{3}$ Jing Lu, ${ }^{4}$ \\ Dangwei Wang, ${ }^{5}$ Lu Chen, ${ }^{6}$ and Xinyuan Liu ${ }^{7}$ \\ ${ }^{1}$ College of Resources and Environmental Science, South-Central University for Nationalities, Wuhan 430074, China \\ ${ }^{2}$ State Key Laboratory of Hydrology-Water Resources and Hydraulic Engineering, Hohai University, Nanjing 210098, China \\ ${ }^{3}$ Changjiang Water Resources Protection Institute, Wuhan 430010, China \\ ${ }^{4}$ State Key Laboratory of Water Resources and Hydropower Engineering Science, Wuhan University, Wuhan 430072, China \\ ${ }^{5}$ China Institute of Water Resources and Hydropower Research, Beijing 100038, China \\ ${ }^{6}$ College of Hydropower \& Information Engineering, Huazhong University of Science \& Technology, Wuhan 430074, China \\ ${ }^{7}$ Changjiang River Scientific Research Institute, Wuhan 430010, China
}

Correspondence should be addressed to Junhong Zhang; 2014059@mail.scuec.edu.cn and Lu Chen; chl8505@126.com

Received 19 August 2016; Revised 20 December 2016; Accepted 4 January 2017; Published 14 February 2017

Academic Editor: Maurizio Brocchini

Copyright (C) 2017 Junhong Zhang et al. This is an open access article distributed under the Creative Commons Attribution License, which permits unrestricted use, distribution, and reproduction in any medium, provided the original work is properly cited.

With the rapid development of hydropower exploitation in China, changes in runoff and sediment transport have become a significant issue that cannot be neglected. In this study, the Han River was selected as a study case, where the runoff variation and changes in sediment load at the Baihe, Huangjiagang, Huangzhuang, and Xiantao stations were analyzed in different time periods. The results indicate that impact of cascade hydropower exploitation on runoff and sediment transport is significantly different even during the same time periods. After reservoir regulation, the decreasing of sediment load is faster than that of runoff. Strong positive correlation between runoff and sediment load exists during different time periods, while reservoir operation leads to different turning points at the Baihe, Huangjiagang, Huangzhuang, and Xiantao stations in the middle and lower Han River. As a key driving factor, runoff variation contributed to sediment transport with different impact index $C_{R}$. The impact index $C_{R}$ before and after the first change point at the Baihe, Huangjiagang, Huangzhuang, and Xiantao stations is $43.35 \%,-3.68 \%, 11.17 \%$, and $30.12 \%$, respectively. This study helps us understand and evaluate the hydrological changes under cascade hydropower exploitation in the middle and lower Han River.

\section{Introduction}

With the rapid development of the social economy and improvement of modern science and technology, human activities have affected the environment deeply, which has attracted extensive attention. In particular, a large number of water conservancy projects were built in recent years, and water resource that humans must depend on has been under control to a certain degree. However, runoff process and sediment transport in rivers have also changed greatly. How to evaluate the influence of water resource exploitation on surface runoff and sediment yield and predict the tendency of hydrological variation have been a significant issue [1]. Thomas [2] first carried out his research on changes in runoff and sediment in the Colorado River, and he pointed out that annual sediment yield at the Grand Canyon gauging station totally reduced about $0.45 \sim 1.54 \times 10^{8}$ tons during 1941 1944, while the runoff volume at the same station had no obvious changes. Meade and Parker [3] also studied the influence of dams built along the Colorado River on sediment transport and indicated that establishment of the Hoover Dam was one of the most important reasons for the great reduction of annual sediment yield. In addition, the decrease of sediment yield and sediment deposition in tributaries has been playing an increasingly important role in some rivers, which can reflect the relationship between fluvial process and changes of hydrologic regimes to a certain degree in the lower Yangtze River [4]. 


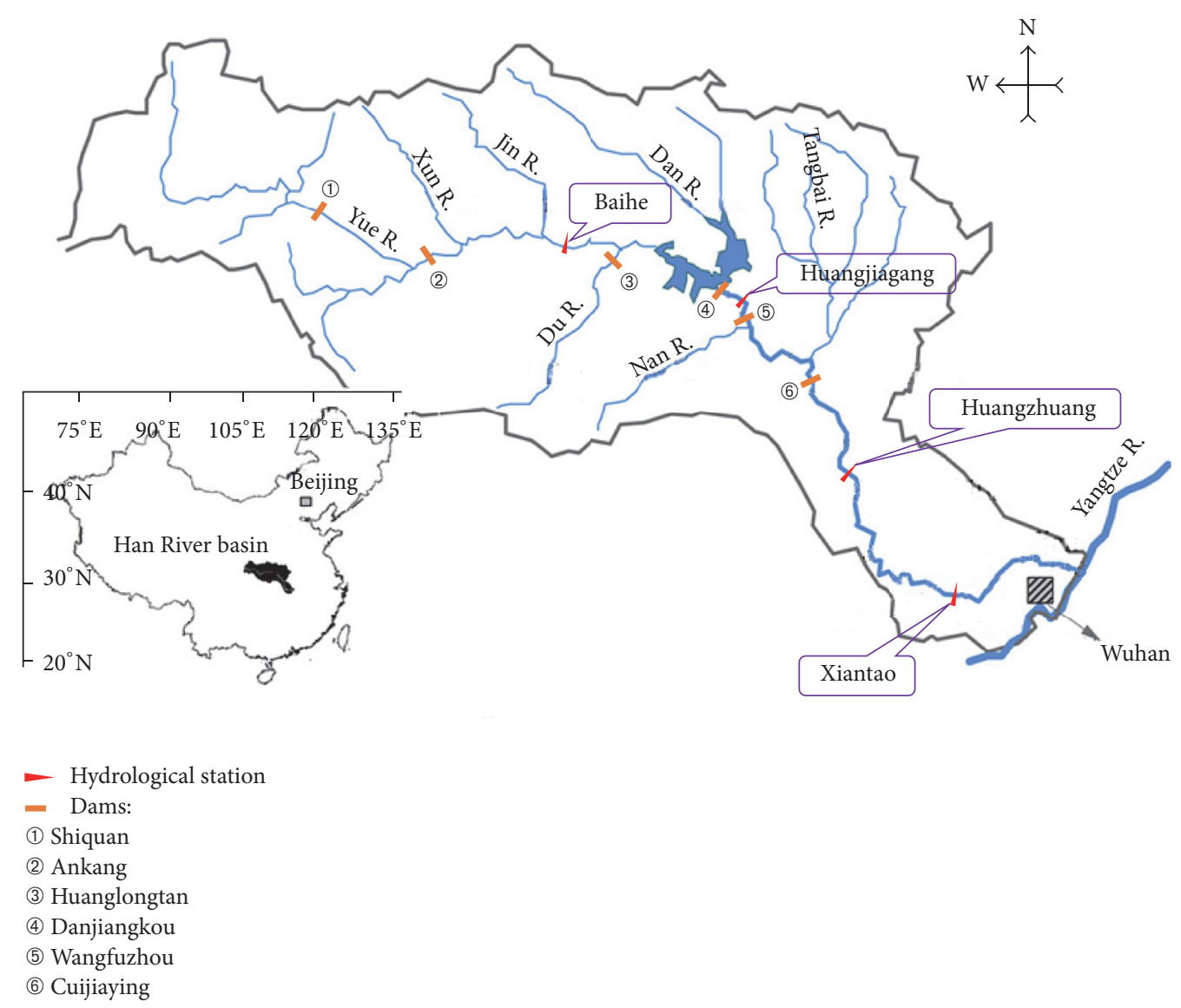

Figure 1: Locations of the Han River, tributaries, dams, and hydrological stations, whose data were used in this study.

In the past 50 years, the process of runoff and sediment has experienced a great change with comprehensive exploitation and utilization of water resources in China [5]. After operation of the Three Gorges Reservoir in the Yangtze River, mean discharge during flood seasons reduced greatly but increased a certain degree in drought periods downstream of the dam [6]. Li and Gu [7] carried out a systematical study of variation of erosion and deposition in channels downstream of the Yangtze Reservoir and indicated that sediment runoff of different size groups would never exceed the ones before the operation of the Three Gorges Dam in spite of riverbed scouring and sediment concentration recovery on a large scale. Moreover, the decrease of sediment concentration downstream of dams greatly increased size of the median diameter $\left(D_{50}\right)$ of suspended sediments and bed material load, which contributed a lot to bed coarsening along the channels [8]. Dai et al. [9] discussed the floods that occurred in the Yangtze and the Han River basins and found out that they have a great probability of flood coincidence. This is because the flood seasons of the middle Yangtze River and the lower Han River usually share the same periods which is from July to September every year. Therefore, a spillway was suggested to be built to connect the Yangtze River and the Han River in order to relieve flood disasters in these regions [10]. It thence appears that the intervention of human activities, especially the establishment of the cascade reservoirs, caused some changes of hydrologic regime in these river basins, which ultimately resulted in a spatial and temporal redistribution of runoff and sediment transport. Therefore, we need to have a further study and analysis on the variation rules of runoff and sediment transport considering both the natural changes and reservoir regulation. Based on these, we can better predict the trends and characteristics of runoff and sediment transport in these regions.

The objective of this paper is therefore to investigate the influence of cascade hydropower exploitation on runoff and sediment transport. The Han River basin was selected as a case study. The effects caused by a series of water conservancy facilities, such as the Danjiangkou, Wangfuzhou, and Cuijiaying reservoirs, were analyzed. The dominant factors that affect the changes in runoff and sediment transport were identified and evaluated in order to provide a scientific basis for the comprehensive management in the Han River basin.

\section{Study Area and Data}

2.1. Study Area. The Han River, located in central China (Figure 1), is the largest branch of the Yangtze River. The main stream of the Han River is $1577 \mathrm{~km}$ in length with a drainage area of $159,000 \mathrm{~km}^{2}$. The Han River basin is in a subtropical monsoon climate region with annual precipitation of about 700-1000 mm [11]. Annual precipitation gradually increases 
TABLE 1: Detailed hydrological data information used in this study.

\begin{tabular}{lccc}
\hline \multirow{2}{*}{ Stations } & \multirow{2}{*}{ Drainage area $\left(\mathrm{km}^{2}\right)$} & \multicolumn{2}{c}{ Data length } \\
& & Runoff & Sediment load \\
\hline Baihe & 59115 & $1955-2012$ & $1955-2005$ \\
Huangjiagang & 95217 & $1955-2013$ & $1955-2013$ \\
Huangzhuang & 147528 & $1955-2013$ & $1955-2013$ \\
Xiantao & 216579 & $1955-2012$ & $1955-2006$ \\
\hline
\end{tabular}

from upper to lower basin and decreases from the south to the north in the whole basin. About $80 \%$ precipitations occur during the period from May to October, and the largest amount of river runoff is concentrated in this period correspondingly. From the northwest to the southeast, the Han River basin is divided into three subbasins, namely, the upper valley, the middle river basin, and the lower river basin. The upper valley generally covered mountainous and hilly areas. It extends up to the Danjiangkou reservoir (draining about $55 \%$ of contributing area), which is the source of water for the well-known middle route of South-North Water Transfer Project (SNWTP) in China [12]. The middle river basin refers to the section from Danjiangkou to Huangzhuang (draining about $21 \%$ of contributing area). And the lower river basin is from Huangzhuang to Hankou [13]. With the rapid development of water resources in the middle and lower Han River, a scheduling system of cascade reservoirs has been formed [14]. The Danjiangkou reservoir is the largest hydraulic engineering work with total storage capacity to 17.4 billion $\mathrm{m}^{3}$, which plays an important role in flood control, power generation, navigation, and irrigation. Besides the Danjiangkou reservoir, a series of large-scale water projects were built along the Han River basin (as shown in Figure 1).

2.2. Data Collection. Hydrological data of annual runoff and suspended sediment load of Huangjiagang, Xiangyang, Huangzhuang, and Xiantao stations along mainstream of the Han River were collected from the Changjiang Water Resources Commission, China (CWRC) $[15,16]$. The CWRC not only monitored the runoff process but also maintained full-time suspended sediment at these hydrological stations. Therefore, we collected the long-term data series of runoff and sediment of each hydrological station for this study. Suspended sediment load measured at these stations was used as the sediment load data in this paper. The total annual runoff and sediment load data were used in this study. The station locations and data periods are shown in Figure 1 and Table 1. Homogeneity and reliability of the runoff and sediment data have been carefully checked and firmly controlled by the CWRC before they were released. The data series used in this study are consistent and without any missing data. Correlation analysis of all the collected data series was performed in this study using modified Mann-Kendall trend test.

\section{Methodology}

In order to investigate the changing trends of runoff and sediment transport in the Han River basin, five-year moving average method, rank-based Mann-Kendall method, and slope change ratio of cumulative quantity method were used in this study to test the evolutionary trend of runoff and sediment transport in the past decades.

3.1. Multiyear Moving Average of Data Series. Average values of data series can be calculated from the former and later period values of hydrological sequence $x_{1}, x_{2}, \ldots, x_{n}$; thus, a new sequence $y_{i}$ can be defined by the series of average values. This data processing mode makes original sequence much more smoothly, therefore, which is called moving average method [17]. Mathematical expression of the method is given by

$$
y_{i}=\frac{1}{2 k+1} \sum_{i=-k}^{k} x_{t+i}
$$

where $2 k+1$ is the step size of data series; $x_{t+i}$ is ordinal data series with time $t$. In this study, $k$ was assigned to 2 , which means that five-year moving average method was used to deal with the hydrological data series. If there are trend ingredients in the sequence $x_{t+i}$, the new sequence $y_{t}$ can show them clearly.

3.2. Rank-Based Mann-Kendall Test. Rank-based MannKendall test is a nonparametric statistic method to detect monotonic trends in series of environmental data, climate data, or hydrological data $[18,19]$. This method was also adopted to test abrupt changes in the data series. Because of no distribution forms of data series having to be assumed in advance and greater power in trend analysis, the MannKendall test is highly recommended by the World Meteorological Organization [20]. Now it has been widely used in the field of hydrology and meteorology [21]. In the Mann-Kendall test, the null hypothesis, $H_{0}$, is that the data come from a population with independent realizations and are identically distributed. The alternative hypothesis, $H_{1}$, is that the data follow a monotonic trend. For example, there is a time series $X$ with sample size $n$. The Mann-Kendall test statistic $M_{k}$ is calculated by

$$
\begin{aligned}
M_{k} & =\sum_{i=1}^{k} r_{i}, \quad(k=1,2, \ldots, n), \\
r_{i} & =\left\{\begin{array}{ll}
1, & x_{i}>x_{j}, \\
0, & x_{i}<x_{j},
\end{array} \quad(j=1,2, \ldots, i) .\right.
\end{aligned}
$$

Under the null hypothesis of the sample, the statistic $M_{k}$ is standardized as $U_{k}$ :

$$
U_{k}=\frac{M_{k}-E\left(M_{k}\right)}{\sqrt{\operatorname{var}\left(M_{k}\right)}}, \quad(k=1,2, \ldots, n),
$$

where $U_{1}=0$; and $E\left(M_{k}\right)$ and $\operatorname{var}\left(M_{k}\right)$ are mathematical expectation and variance of $M_{k}$, respectively. When the data 
obtained over time are independent, $E\left(M_{k}\right)$ and $\operatorname{var}\left(M_{k}\right)$ can be calculated by

$$
\begin{aligned}
\operatorname{var}\left(M_{k}\right) & =\frac{n(n-1)(2 n+5)}{72}, \\
E\left(M_{k}\right) & =\frac{n(n-1)}{4} .
\end{aligned}
$$

The total annual data which were considered in this study are usually taken as independent and identically distributed in hydrology. Therefore, this method was used in this study.

$U_{k}$ follows the standard normal distribution after the standardization mentioned above. Under a given confidence level $\alpha$, if $\left|U_{k}\right|>U_{\alpha / 2}$ exists, the null hypothesis should be accepted, where $U_{\alpha / 2}$ is the critical value of the standard normal distribution with an exceeding probability $\alpha / 2$. In other words, the rising or downward trend of data series is inconspicuous. On the contrary, it indicated that there is a conspicuous developing trend of the data series. In our study, the significant level of $\alpha$ was assigned 5\%.

Besides the traditional Mann-Kendall test, we also calculated the statistic variables $M_{k}^{\prime}$, $\operatorname{var}^{\prime}\left(M_{k}\right), E^{\prime}\left(M_{k}\right)$, and $U_{k}^{\prime}$ for the retrograde sample $\left(x_{n}, x_{n-1}, \ldots, x_{1}\right)$ in the same way as shown in (1)-(4). The calculated values of $U_{k}$ and $U_{k}^{\prime}$ based on the progressive and retrograde series were assigned to $Z_{k}$ and $Z_{k}^{\prime}$, respectively. Two curves, namely, $Z_{k}(t)$ and $Z_{k}^{\prime}(t)$, can be drawn using the calculated $U_{k}$ and $U_{k}^{\prime}$ values. The points of intersection of those two curves within the confidence interval indicted the beginning time of abrupt changes in the calculated time series.

3.3. Analysis of Mass Curves. A double mass curve is a plot of cumulative values of one variable against the accumulation of another quantity during the same time period. It is used to determine the changes between the two datasets. If the two datasets are consistent, the slope of the double mass curve is linear. A break in the slope of the curve would indicate that conditions have changed. The method was introduced in this paper to evaluate the impact of runoff variation on sediment transport in the Han River basin in a quantitative manner. Generally, the changes in runoff directly affect the sediment transport. Since the slope of double mass curves represents the proportionality between the two quantities, the contribution rate of runoff variation to sediment transport can be expressed as the slope of these curves.

In order to determine whether these turning points are caused by runoff variation or sediment changes, the single mass curves are also involved in this study. The changing ratio of the slope of single mass is introduced in this study to discuss the changes before and after the turning points determined by double mass curves.

A linear relationship was assumed before and after any abrupt changes; the changing ratio of the slope of single mass curves can be expressed as

$$
R_{S R}=\frac{100\left(S_{\mathrm{Ra}}-S_{\mathrm{Rb}}\right)}{S_{\mathrm{Rb}}}=100\left(\frac{S_{\mathrm{Ra}}}{S_{\mathrm{Rb}}}-1\right),
$$

where $S_{\mathrm{Ra}}$ and $S_{\mathrm{Rb}}$ are the slopes of double mass curves before and after abrupt changes; $R_{\mathrm{SR}}$ is the changing ratio of the slope of the single mass curve.

Similarly, the changing ratio of the slope of cumulative sediment load can be expressed as

$$
R_{\mathrm{SS}}=\frac{100\left(S_{\mathrm{Sa}}-S_{\mathrm{Sb}}\right)}{S_{\mathrm{Sb}}}=100\left(\frac{S_{\mathrm{Sa}}}{S_{\mathrm{Sb}}}-1\right),
$$

where $S_{\mathrm{Sa}}$ and $S_{\mathrm{Sb}}$ are the slopes of sediment load accumulative curves before and after abrupt changes; $R_{\mathrm{SS}}$ is the change ratio of slope of cumulative sediment load over time.

Therefore, the extent of runoff variation impact on the sediment transport before and after turning time can be estimated as $C_{R}$ [22]:

$$
C_{R}=\frac{100 R_{S R}}{R_{\mathrm{SS}}}=\frac{100\left(S_{\mathrm{Ra}} / S_{\mathrm{Rb}}-1\right)}{\left(S_{\mathrm{Sa}} / S_{\mathrm{Sb}}-1\right)} .
$$

When the abrupt changes and linear trends were detected in the time series, the impact of runoff variation on sediment transport before and after abrupt changes can be quantitatively estimated by (8).

\section{Results and Discussion}

4.1. Runoff Variations. The data used in this study were collected from four gauging stations (Baihe, Huangjiagang, Huangzhuang, and Xiantao) in the Han River basin, which covered the original data of long-term records of runoff and sediment discharge for nearly 60 years (1955-2013). In order to detect the monotonic trend and analyze the changing points of runoff under the exploitation of cascade hydropower, the annual runoff data series at the four gauging stations were used.

4.1.1. Tendency of Runoff Changes. Based on the data series of runoff in the Han River basin, the process diagrams of the runoff at the four stations were obtained using the five-year moving mean method. The results are shown in Figure 2.

It can be seen from Figure 2 that there is a downward trend in runoff at all the four stations in the Han River basin, having a conspicuous runoff fluctuation between different years. In addition, from the year of 1980, there is a decrease trend at the Baihe, Huangjiagang, and Huangzhuang stations, and it began to gradually rise again at the end of the 20th century. However, this changing process was not obvious at the Xiantao station, which is located in the lower Han River. Linear-regression curves of the runoff data series were shown in Figure 2 as well, which also indicates that there is a decreasing trend of runoff over years in the middle and lower Han River.

In addition, the trend and slope of the linear-regression line are nearly the same at the stations (b) Huangjiagang, (c) Huangzhuang, and (d) Xiantao. This may be related to the layout position of the three stations. It can be seen that the maximum runoff occurred in 1964 at Huangjiagang, Huangzhuang, and Xiantao station, while the maximum runoff did not appear at Baihe station in that year. Therefore, it can be 


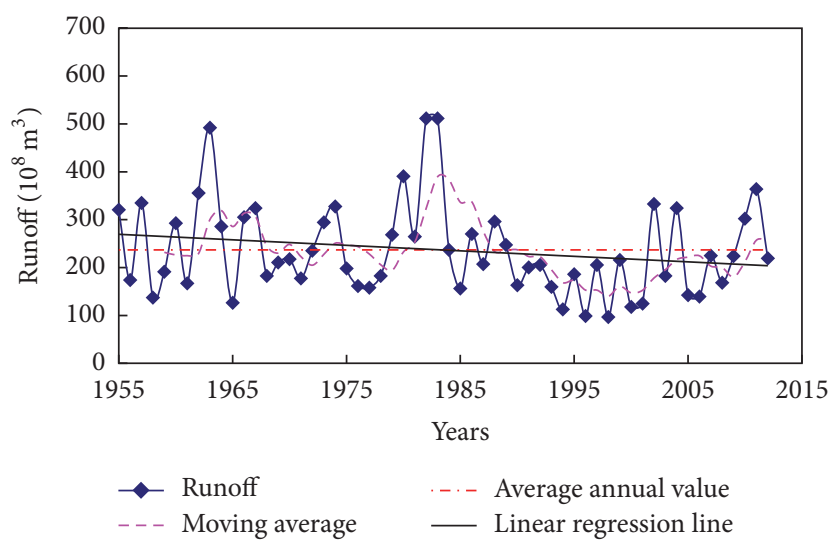

(a) Baihe

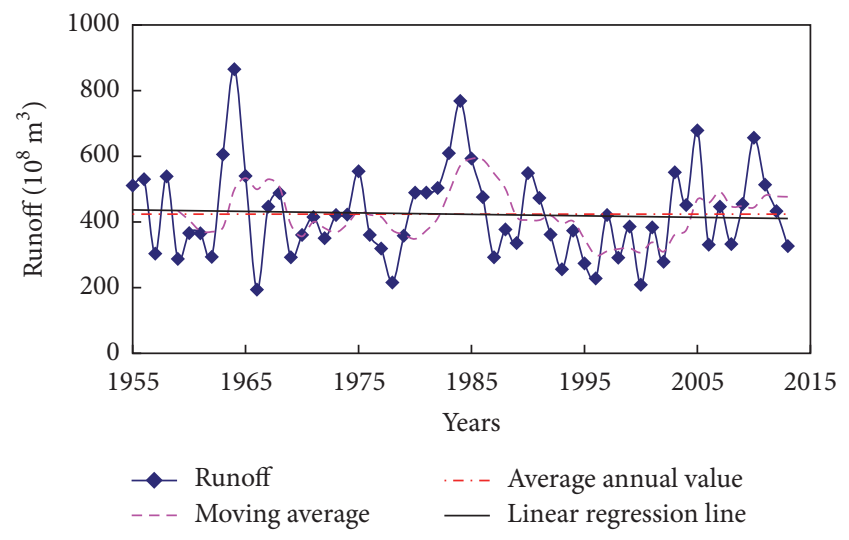

(c) Huangzhuang

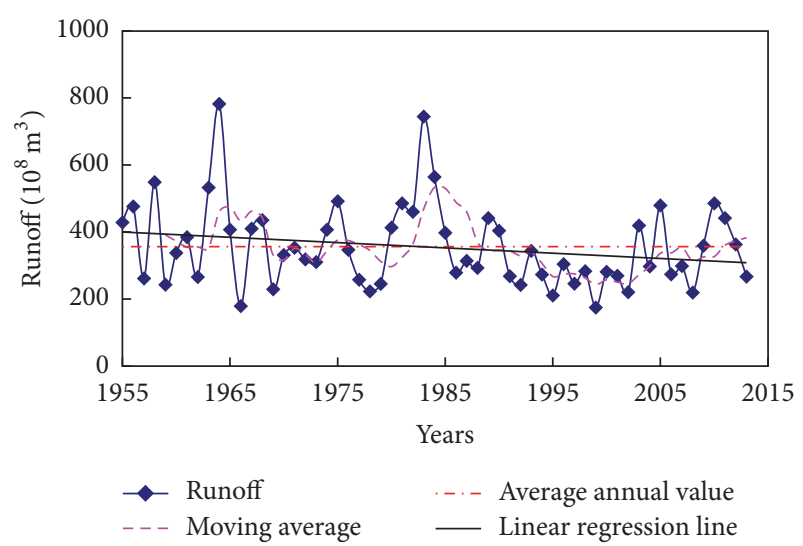

(b) Huangjiagang

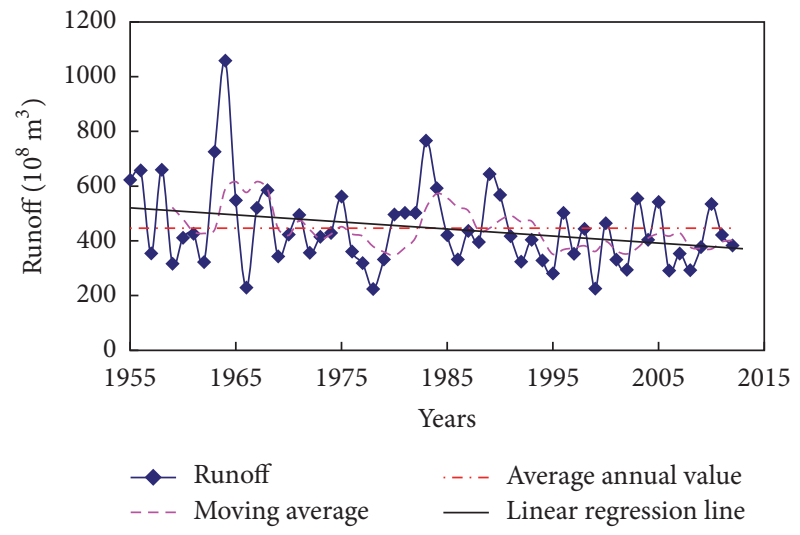

(d) Xiantao

FIgURE 2: The runoff variation at the four gauging stations in the Han River basin.

inferred that the main runoff is from the middle and lower Han River basin and its tributaries, including Danjiang River, Tangbai River, and Nan River. Moreover, it can be seen from Figure 2 that there was also a larger flood that occurred in 1983 , and flood peak appeared at all the four gauging stations at the same period. Therefore, the runoff changes have a strong regional correlation, which has been bound up with the distribution of heavy rain in the Han River basin [23].

4.1.2. Analysis of Abrupt Changes in Runoff. Based on the method of rank-based Mann-Kendall, the statistics of runoff data series were calculated, and results of abrupt changes are shown in Figure 3.

The up and lower dotted lines are the confidence intervals at the $5 \%$ significance level in the Mann-Kendall test. It can be seen from Figure 3(a) that there is a fluctuation of $Z_{k}$ and $Z_{k}^{\prime}$ values within a narrow range before the year of 1989 . The curves of $Z_{k}(t)$ and $Z_{k}^{\prime}(t)$ intersected in 1989 , which indicates that an abrupt change in the runoff at the Baihe station occurs at that time. This is because of the building of the Ankang reservoir. The runoff variation at the Baihe station has a close relationship with the operation of Ankang reservoir located in the upper Han River, which has been in use since 1989 [24]. After 1989, the runoff at Baihe station shows a downward trend, because some of the runoff was stored in the reservoir. Especially in the year 2000, the value of $Z_{k}$ is below the lower confidence interval, which means the decreasing trend is very significant.

In addition, the curves of $Z_{k}(t)$ and $Z_{k}^{\prime}(t)$ for the other three stations (b), (c), and (d) changed evidently with multiple intersection points, which shows that abrupt changes of runoff may occur frequently from 1955 . However, not all the intersection points are change points. It needs us to check the real ones. Because the Danjiangkou dam has a significant effect on flood control, the curve of $Z_{k}(t)$ at Huangjiagang station exceeds the confidence interval at the $5 \%$ significant level during the years 1998 to 2010 [25]. Therefore, there was an obvious decrease of runoff at the Huangjiagang station during that period. Moreover, Figure 3 shows that since the values $Z_{k}$ at the Baihe, Huangjiagang, Huangzhuang, and Xiantao stations are consistently below 0 after the years 1990, 1990, 1993, and 1968, respectively, the turning points do not occur at the same time for all the gauging stations. The curves among different sections in the Figure 3 are the results of multifactors, which involve natural elements and human activities [26]. For example, dam regulation, soil and water conservation, and industrial and agricultural water consumption always have different impact on the runoff in different natural river sections and river basins [27]. 

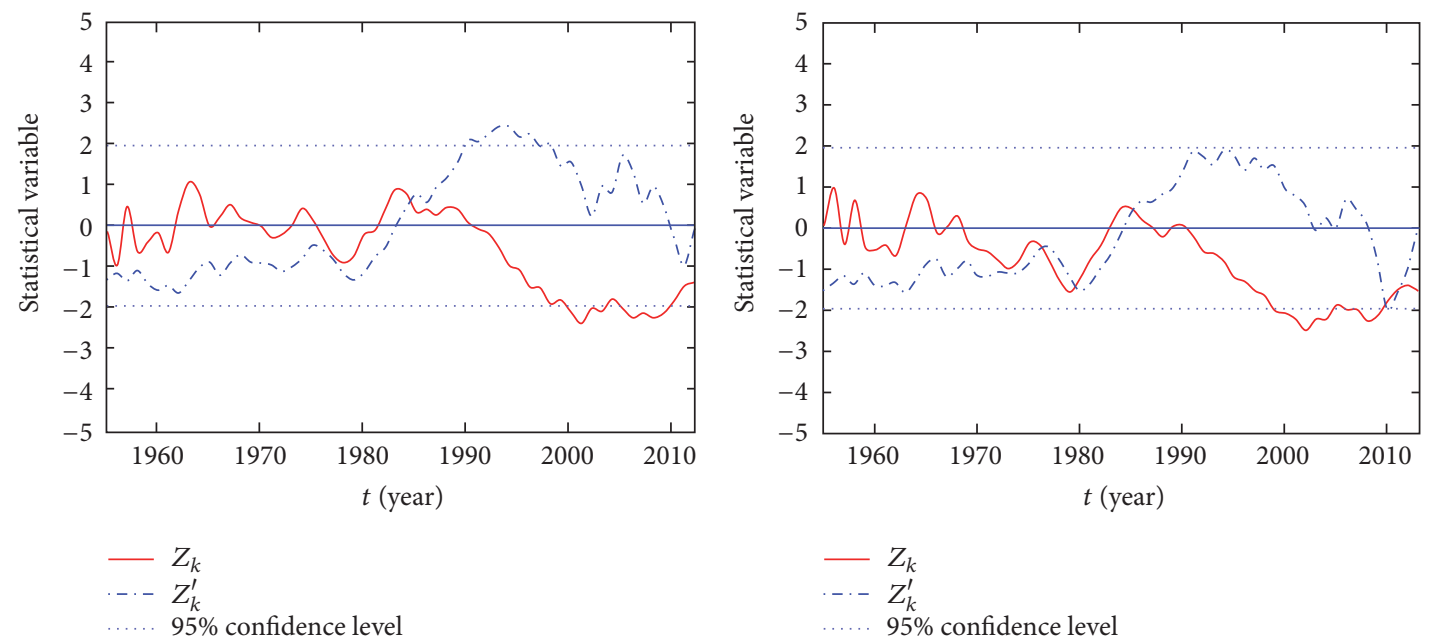

(a) Baihe

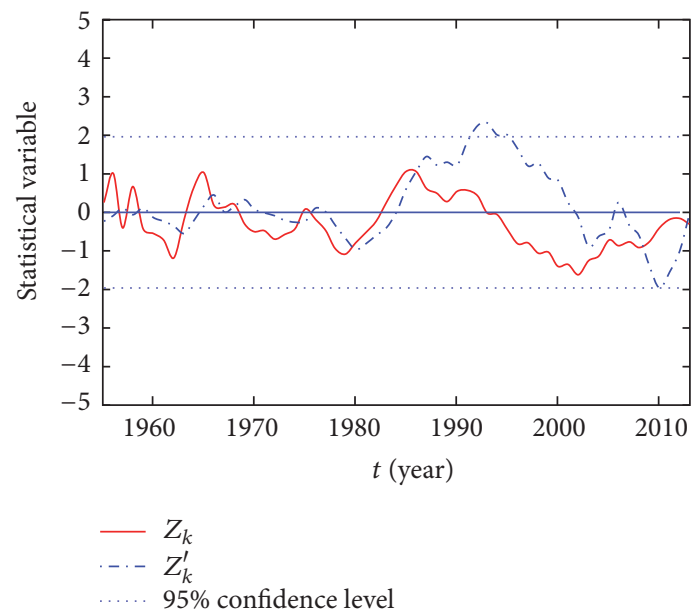

(c) Huangzhuang

(b) Huangjiagang

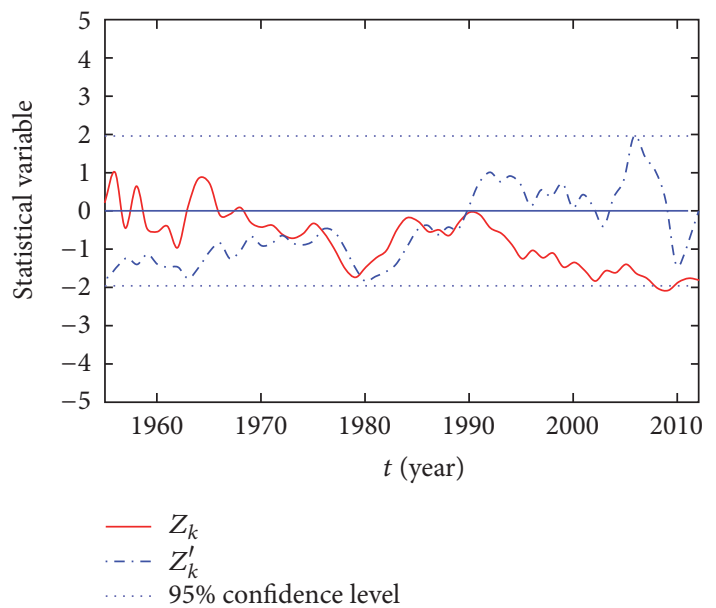

(d) Xiantao

FIgURE 3: $Z_{k}$ and $Z_{k}^{\prime}$ values at the four stations in the Han River basin.

4.2. Changes in Sediment Load. In the same way of the runoff analysis, the trend and abrupt changes in sediment load were analyzed at the four stations based on the annual data series of sediment.

4.2.1. Changing Tendency of Sediment Load. Figure 4 shows the temporal process of sediment transport at different stations in the Han River basin. It can be seen from Figure 4 that there is an obvious downward trend of sediment load in the middle and lower Han River. The Danjiangkou reservoir changes the sediment transport along the channels downstream of dam dramatically [28]. The closer it is to the Danjiangkou dam, the smaller the sediment discharge is. Due to the great decrease in sediment concentration, the sediment load at the Huangjiagang station nearly reduced to zero after the operation of Danjiangkou reservoir since 1968. The influence range is so large that the sediment loads at the Huangzhuang and Xiantao stations also have a dramatic decrease during the same periods. Unlike the Huangjiagang station, there is some degree of increase of sediment discharge gradually at the stations downstream because of flow erosion along the channels and sediment inflow from branches [29]. In contrast to the stations in the middle and lower Han River, the sediment load in the Baihe station has a smooth variation, especially after 1989 due to the sediment control by the Ankang reservoir in the upper Han River [30].

The changing processes of the sediment transport above indicate that the changes in sediment transport do not always show well time consistency at all the hydrological stations in the same river basin [31]. For example, the peak value of sediment load appears at the Huangjiagang, Huangzhuang, and Xiantao stations in 1958, while the sediment load at the Baihe station does not increase greatly at the same time because of the lack of sediment inflow from the branches. In addition, the sediment discharge decreases dramatically at the Huangjiagang, Huangzhuang, and Xiantao stations when the Danjiangkou dam comes into service since 1968. A huge amount of sediment from the upper Han River is deposited in the reservoir area. 


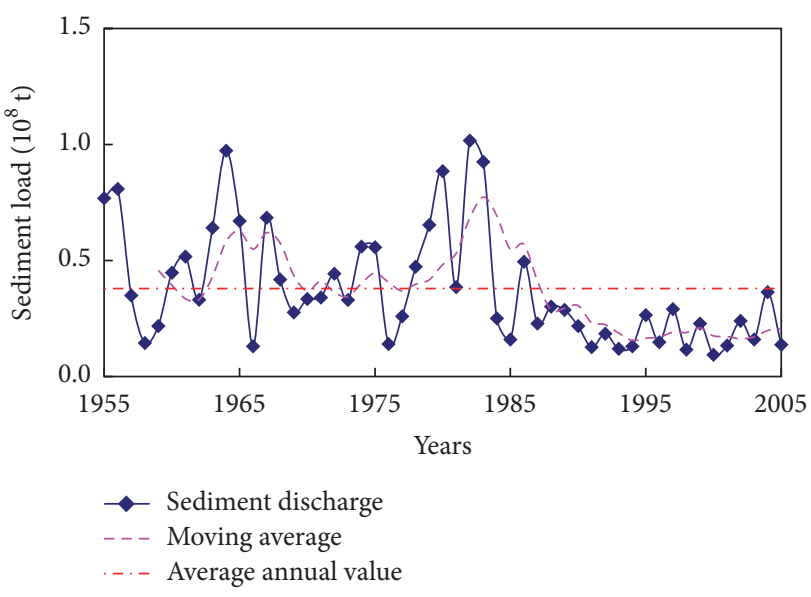

(a) Baihe

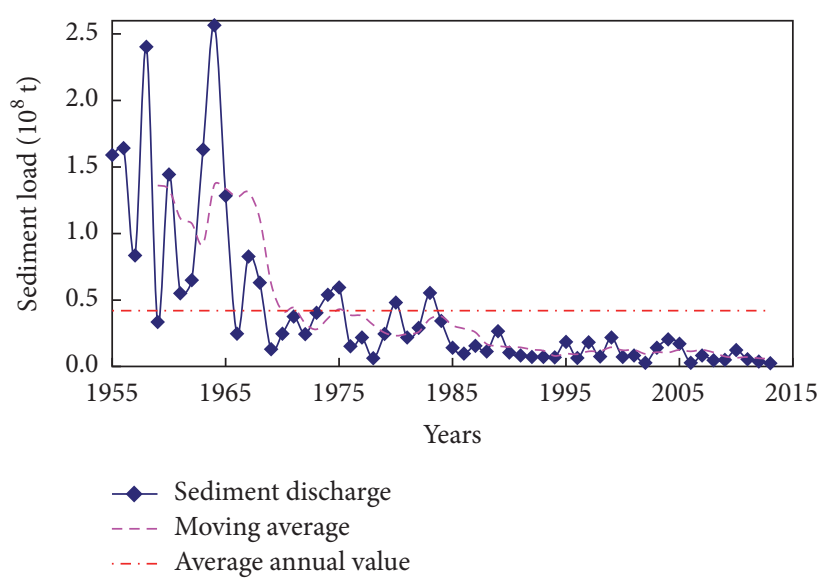

(c) Huangzhuang

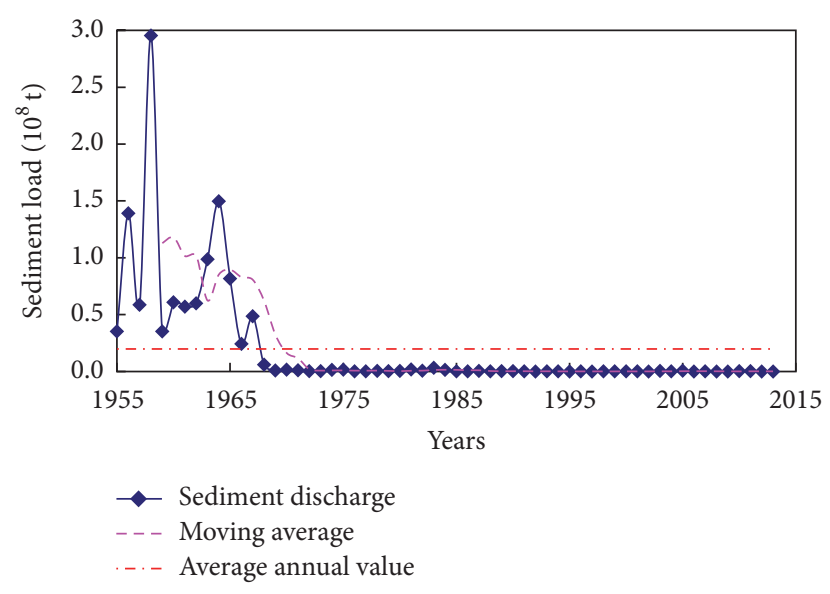

(b) Huangjiagang

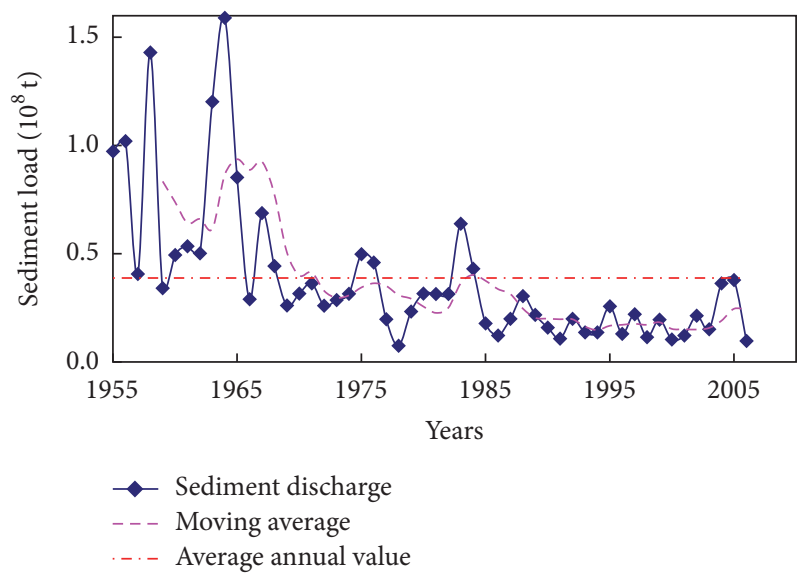

(d) Xiantao

FIGURE 4: Changes in the sediment transport at the four gauging stations in the Han River basin.

4.2.2. Analysis of Abrupt Changes in Sediment Transport. Abrupt changes in sediment transport were detected by the Mann-Kendall test, and the results are shown in Figure 5.

It can be seen from Figure 5 that the sediment transport of the four stations in the Han River basin has an obvious change, because a large amount of sediments is stored in the reservoirs along the river. An abrupt change point of sediment load appears at the Baihe station due to the operation of the Ankang reservoir from 1989, and the statistic $Z_{k}$ exceeds the confidence intervals $(\alpha=0.05)$ in 1992, which indicates a significant decrease in sediment load from then on. The Danjiangkou reservoir has a more serious impact on the sediment transport, since it was put into operation from 1968. The sediment load decreased sharply at the stations along the Han River, because the statistic $Z_{k}$ exceeds the confidence intervals ( $\alpha=0.05)$ at the Huangjiagang, Huangzhuang, and Xiantao stations in 1970s. The intersection points of $Z_{k}(t)$ and $Z_{k}^{\prime}(t)$ curves occur in 1975, 1981, and 1973, respectively. However, the intersection points are beyond the confidence interval drastically at the Huangjiagang, Huangzhuang, and Xiantao stations, which indicates that the beginning time of abrupt changes in the calculated time series should be checked in other ways [32]. Besides the influence of reservoirs operation on sediment transport, the sediment load in the middle and lower Han River is also reduced from upstream to downstream since 1968, which should not be ignored.

\subsection{Changes in Relation between Runoff and Sediment Discharge}

4.3.1. Relation between Runoff and Sediment Transport in Different Periods. It is well known that runoff changes usually have influence on the sediment transport to a certain extent [33]. Therefore, analysis of the relationship between the runoff and sediment is a necessary and significant task. The data series of runoff and sediment load at the four stations were divided into equal length and the mean values were calculated for each period, which are shown in Figures 6 and 7. Based on the mean values of each period, the changes in runoff and sediment in different periods are also shown from these figures. In order to show the values and trends clearly, large time scales (e.g., 10 years) are considered and time-averaged values of runoff and sediment load data for each period were calculated. Therefore, the statistical results 

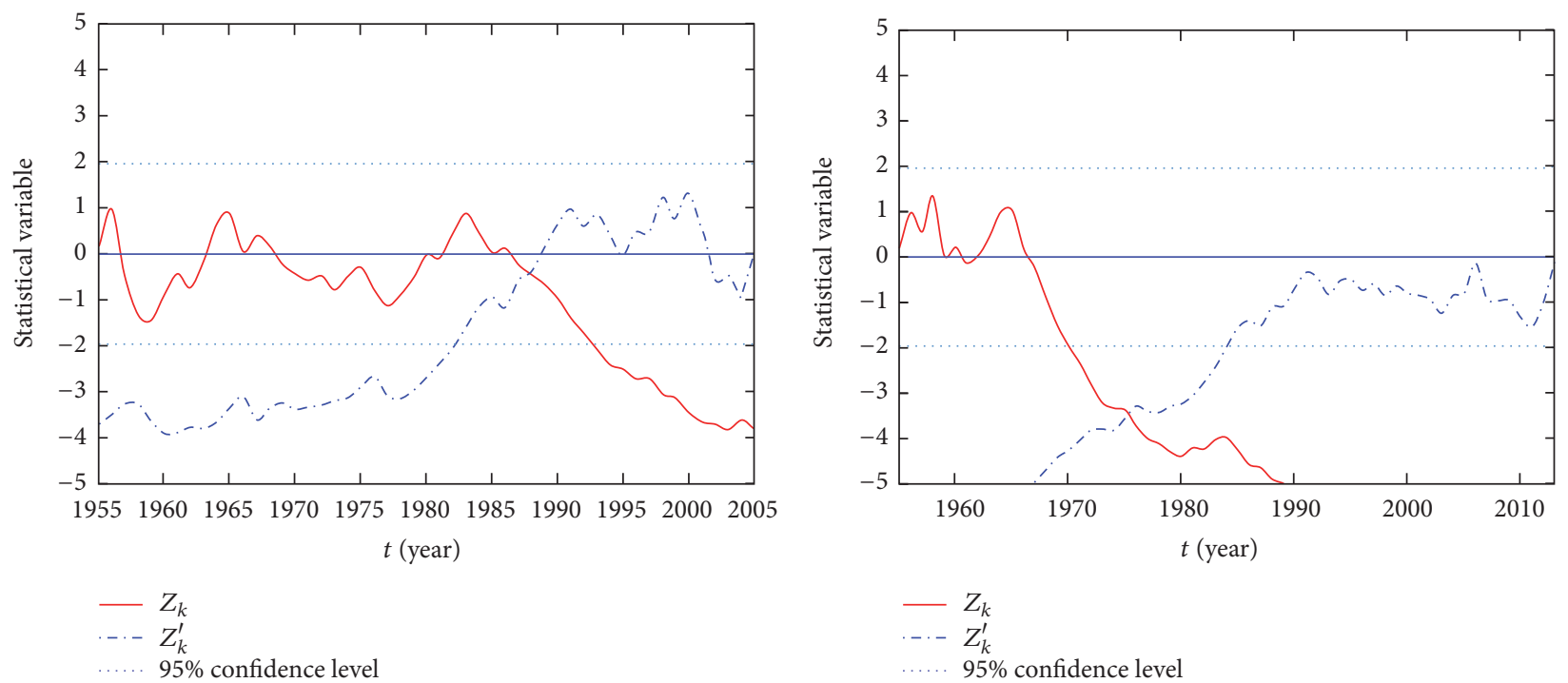

(a) Baihe

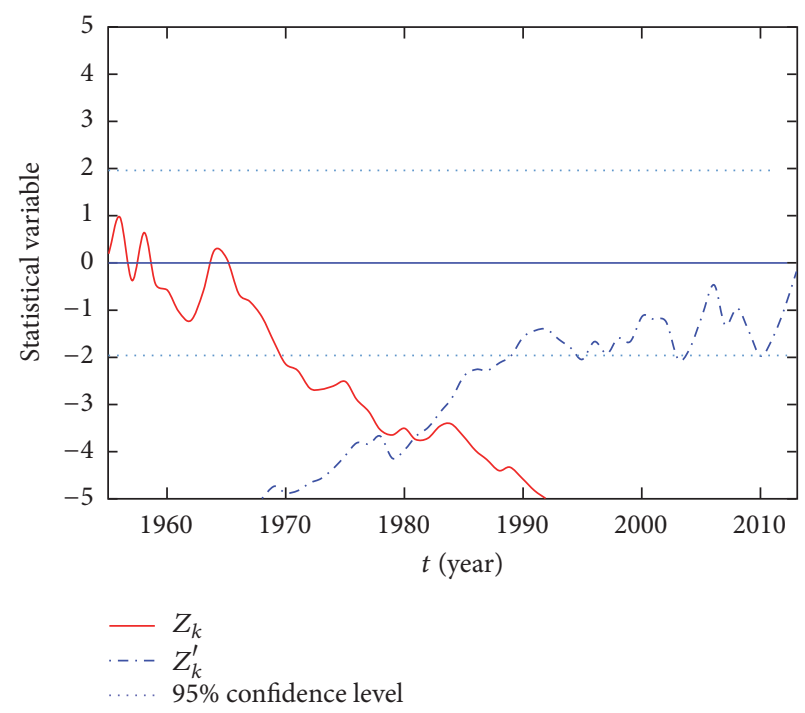

(c) Huangzhuang

(b) Huangjiagang

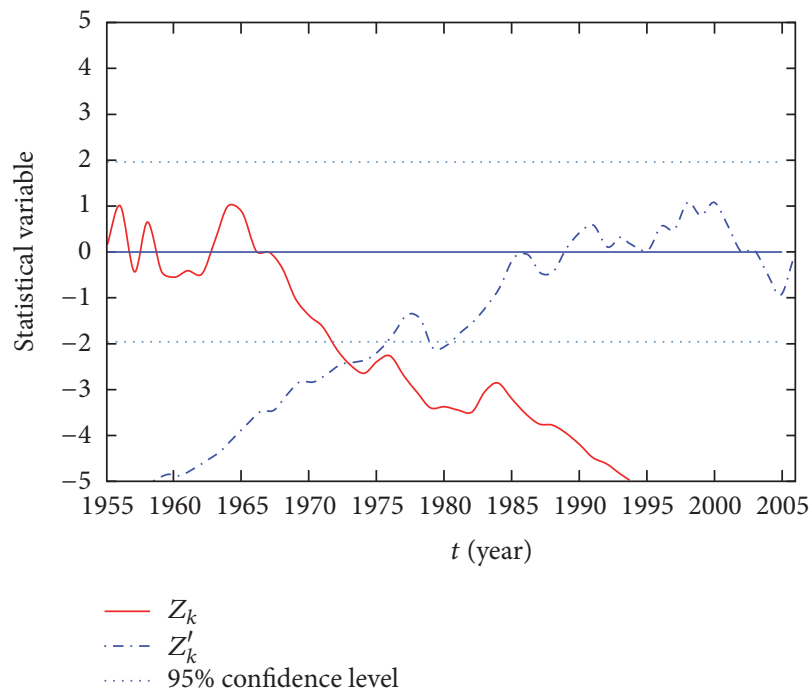

(d) Xiantao

FIgURE 5: Mann-Kendall test curves of sediment transport at the four stations in the middle and lower Han River.

of these figures can reflect the changes in runoff and sediment load during different periods.

It can be seen from Figure 6 that the relationship between runoff and sediment load at the four gauging stations changes greatly in different subperiods. There is a strong correction between runoff and sediment load in the period of 1955-1965 at the Huangjiagang, Huangzhuang, and Xiantao stations due to less influence of human activities. Figure 7(a) shows that the correlation is actually not so large. This is because the Baihe gauging station is located in the upstream of the Han River. Compared with Huangjiagang, Huangzhuang, and Xiantao stations, the sediment load value under the natural condition, namely, from 1955 to 1965, is much smaller. For example, during the years 1955 to 1965, the values of sediment load at the Baihe stations change from 0.1 to $0.910^{8} \mathrm{t}$. On the contrary, in the same period, the values of sediment load at the Huangzhuang station located in the middle of the Han River change from 0.3 to 2.7. In addition, at the Baihe station, the magnitudes of the runoff are also smaller, and the runoff comes from different tributaries. The sediment load of these tributaries is very different. Therefore, the correlation is not large at the Baihe station. Although the dramatic decrease of sediment discharge has broken the original relation between runoff and sediment load because of reservoir operation in the following periods, the overall correlation between them is still positive, as shown in Figure 7. However, these correlations are generally smaller than before. Considering the reservoir operation along the river, the ratio of sediment to runoff acutely decreased with time, especially in the middle and lower Han River (Figure 7).

With the rapid development of economy in the Han River basin, the consumption of domestic and industrial water 


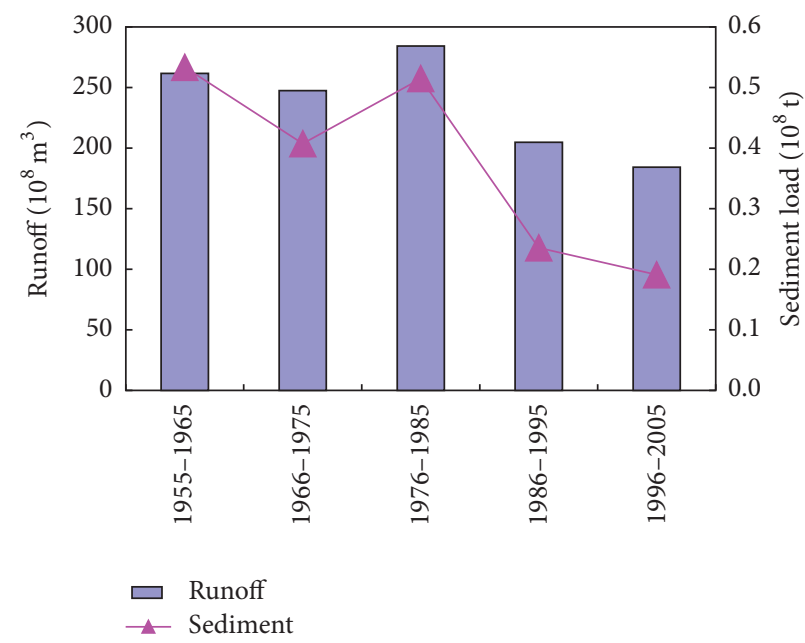

(a) Baihe

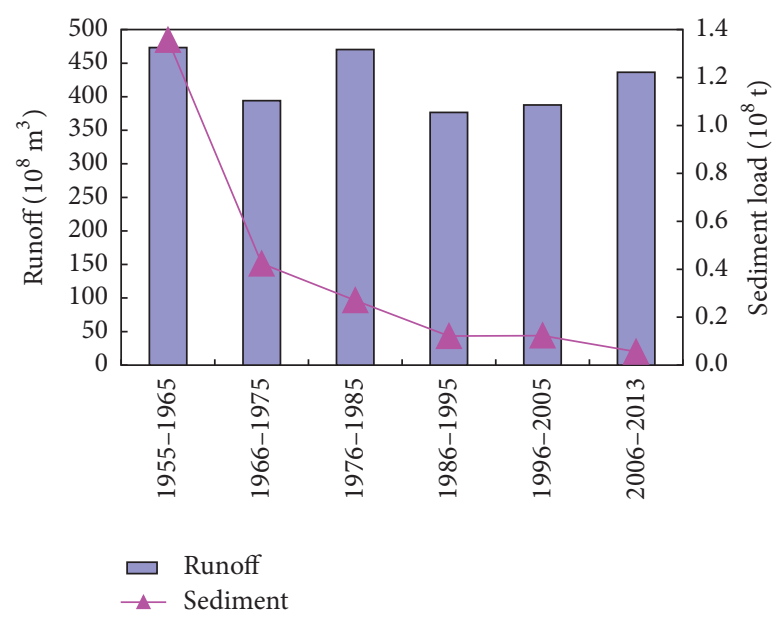

(c) Huangzhuang

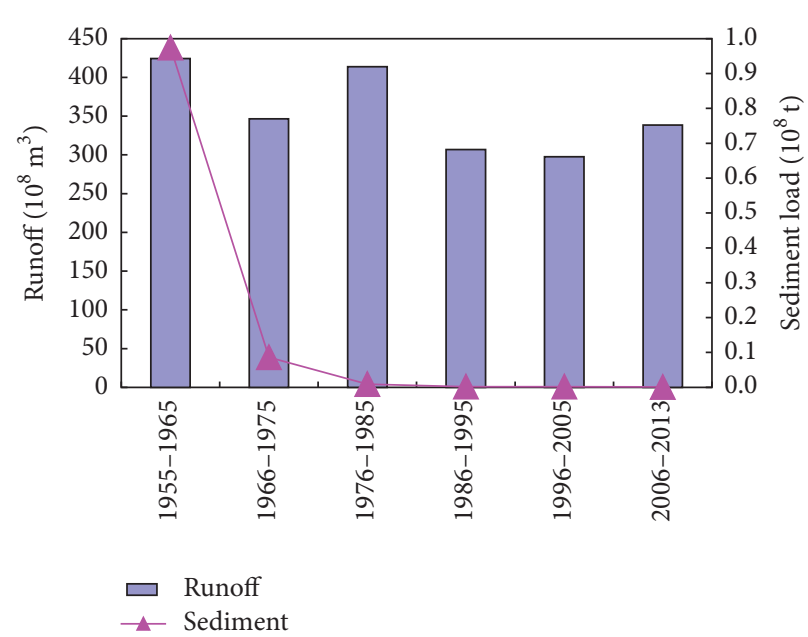

(b) Huangjiagang

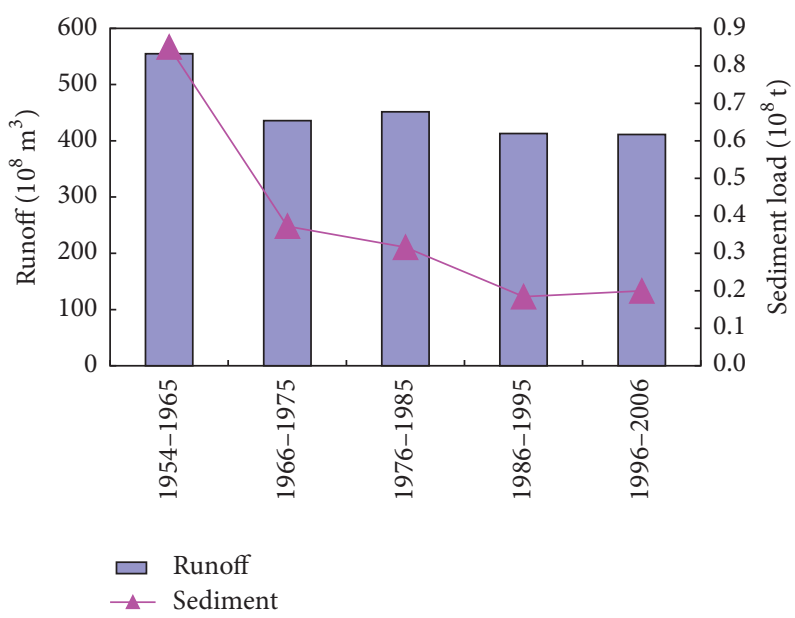

(d) Xiantao

FIGURE 6: Runoff and sediment variation at the four stations in different periods.

increased at a fast pace. Therefore, the runoff at those stations began to decrease to a certain degree after 1985 (as shown in Figure 6). On the other hand, there is a series of water control projects built in the Han River basin during the period 1966 to 1975, such as Shiquan, Danjiangkou, Wangfuzhou, and other hydropower stations, which also resulted in the decrease of runoff and sediment [34]. Considering the impact of cascade reservoir operation, for stations Huangjiagang, Huangzhuang, and Xiantao located downstream of the dam, the sediment load decreased sharply in the period of 1966 to 1975. After the year 1985, the changes in the runoff and sediment load were not so large, and the relationship between runoff and sediment load tended to be stable again [35].

\subsubsection{Impact of Runoff Variation on Sediment Transport under} Reservoir Regulation. The above analysis suggests that there are great differences in the relationship between runoff and sediment load for different periods. When abrupt changes occur at some turning time, the relationship between runoff and sediment load could have a significant change. Therefore, it is very important to find the turning points. However, due to the theoretical limitation of Mann-Kendall test, the turning points cannot be surely determined by the above analysis. We introduced a double mass curve of annual sediment load and runoff to further study the relation between runoff and sediment load. By plotting the accumulation of runoff and sediment load, the data will plot as a straight line, and the slope of this line will represent the constant of proportionality between the two quantities. A break in slope indicates a change in the constant of proportionality [36]. While affected by human activities and other factors, the curve would have a slope change and the degree of these changes can show the intensity of human activities approximately [37]. Therefore, we can identify the turning points of data series by finding out the changes of slope. Results of the double mass curve between runoff and sediment load at the four stations in the Han River basin are shown in Figure 8.

The double mass curve of runoff and sediment load at the Baihe station shows a turning point and the slope of this curve also decreases gradually from 1983 , which indicates a 


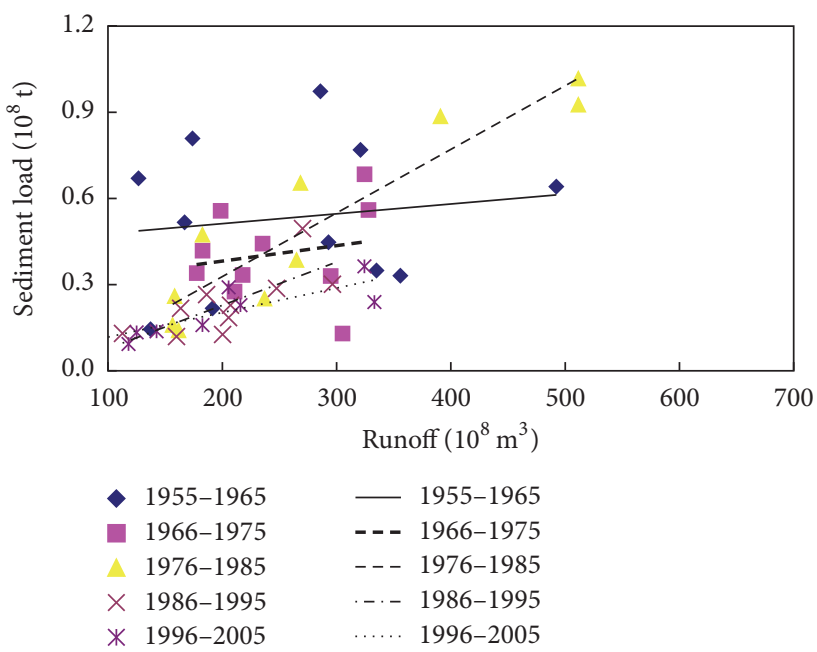

(a) Baihe

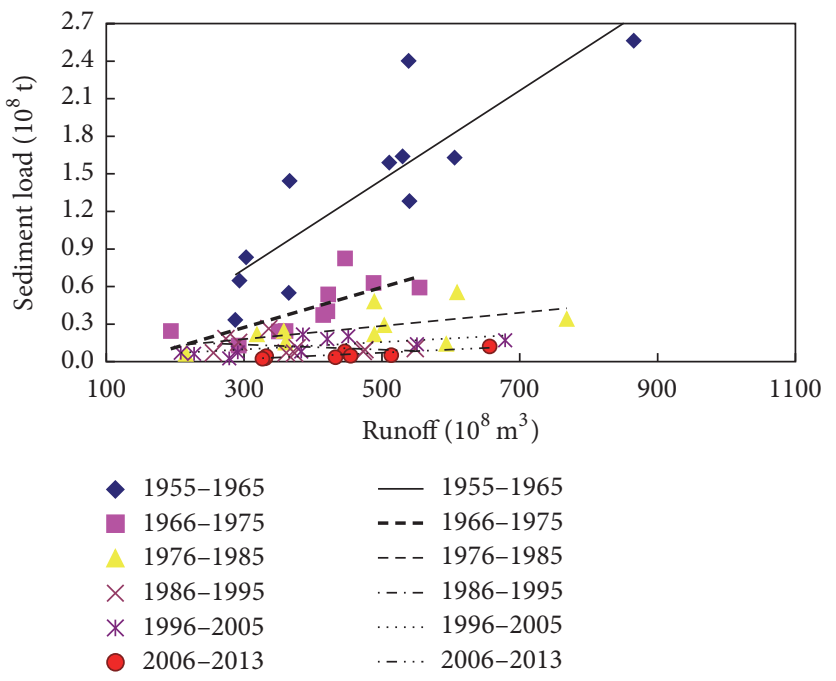

(c) Huangzhuang

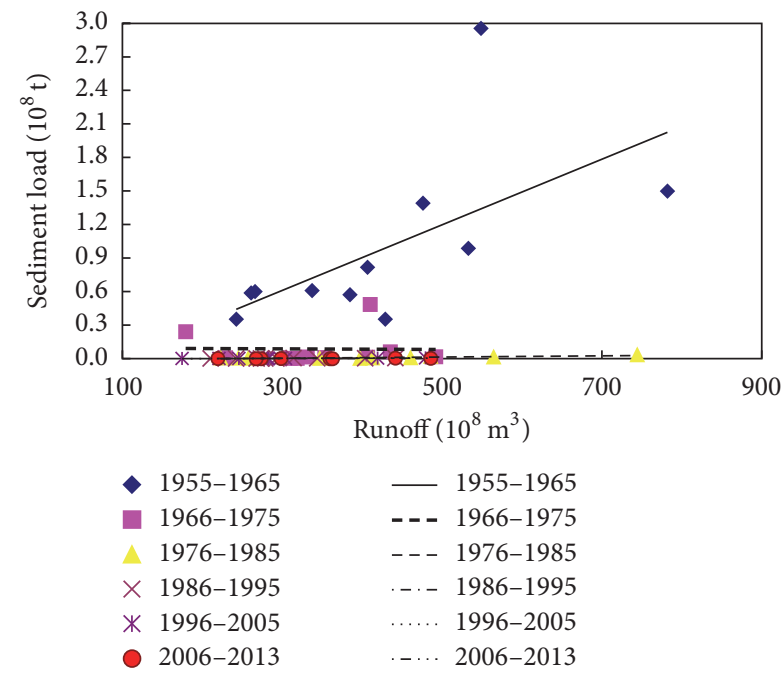

(b) Huangjiagang

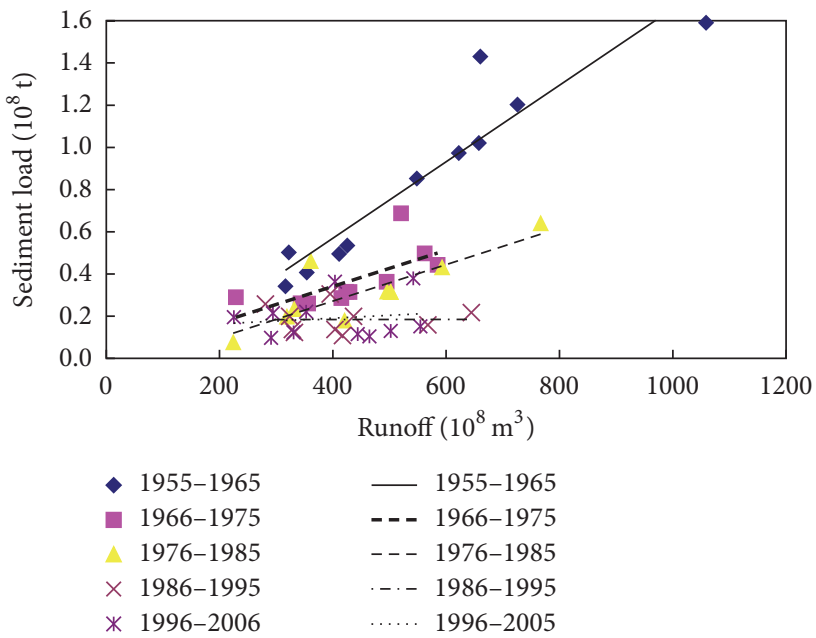

(d) Xiantao

FIGURE 7: Correlations between runoff and sediment at different stations in the middle and lower Han River.

decrease in sediment from this year. For the Huangjiagang station, the abrupt change in 1958 has a close relationship with the construction of the Danjiangkou dam. For Huangjiagang, Huangzhuang, and Xiantao stations, the time of the turning points occurring in 1967 for these three stations coincided with the operation of Danjiangkou reservoir in the Han River basin. And all these three stations are located in the downstream of the Danjiangkou reservoir. The locations of these stations and the time coincidence indicate that these turning points occurring in 1967 are caused by the reservoir operation. Moreover, the dual effects of both reservoir operation and increase in water consumption make the two stations (c) and (d) have abrupt changes in relationship between runoff and sediment transport in 1984. Generally, Figure 8 indicates that reservoir operation has an obvious influence on the relationship between runoff and sediment load in different periods. Therefore, the changes in relationship between runoff and sediment load before and after turning points can reflect the impact of human activities on hydrologic process.

From Figure 8, the potential turning points were derived. But we need to further determine whether these turning points are caused by runoff variation or sediment changes. The single mass curves of runoff and sediment load are given in Figures 9 and 10. The same turning points got in Figure 8 were considered in these figures. It indicates that, from Figure 9, there are no significant changes in runoff before and after the turning points. However, the changes in sediment load are very obvious and coincide with the turning points in Figure 8. These variation trends of runoff and sediment load also demonstrate that the changes in sediment load are not only affected by the runoff. For this reason, we need to investigate the contributions of the runoff variation to changes in the sediment load in the following paragraphs of the paper.

The regression curves are fitted well before and after turning time at the four stations. The slopes of accumulation 


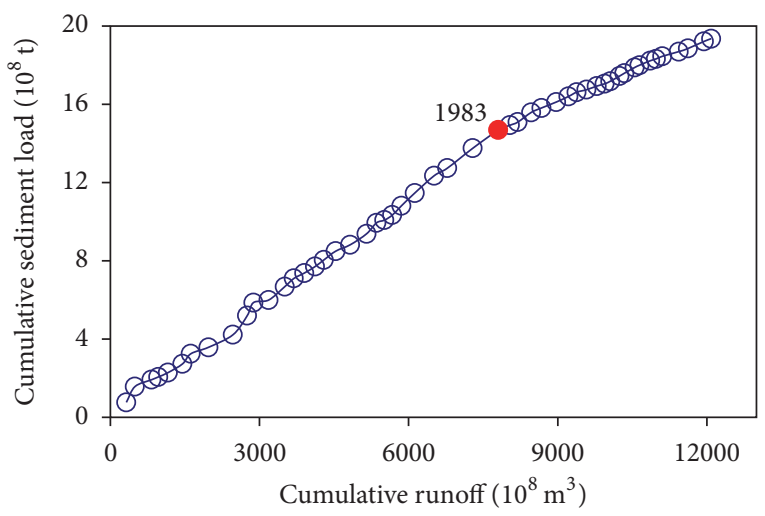

(a) Baihe

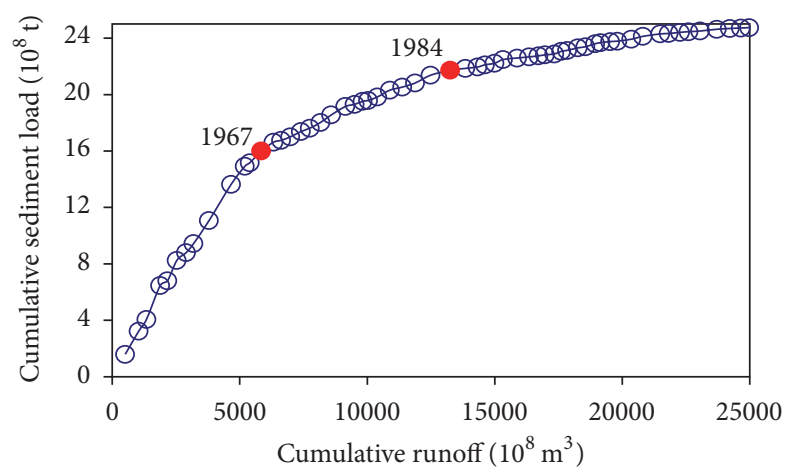

(c) Huangzhuang

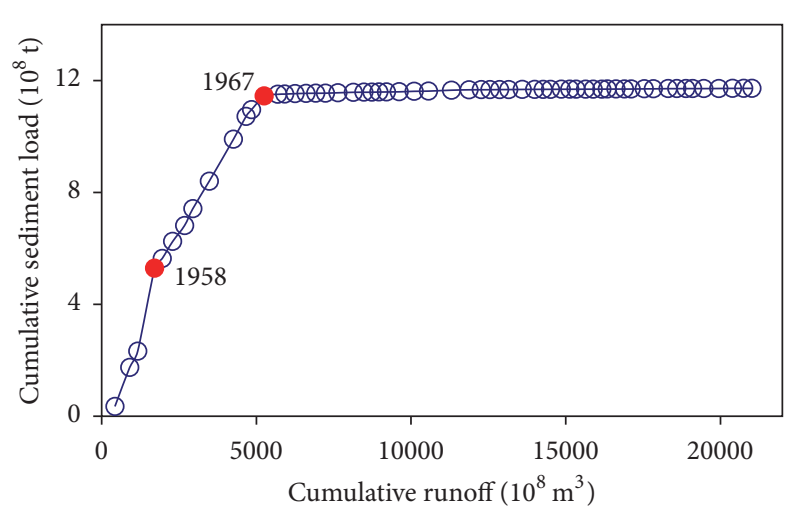

(b) Huangjiagang

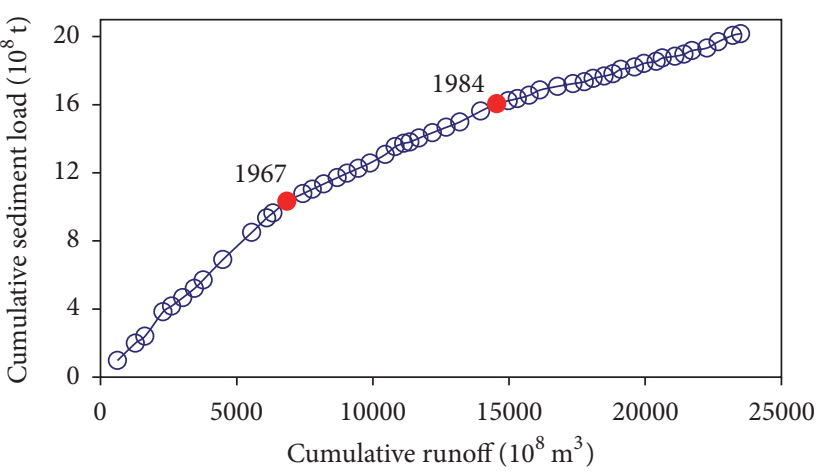

(d) Xiantao

FIgURE 8: Double mass curve of runoff and sediment load at each station along the Han River.

curves of runoff $S_{R}$ and their slope change ratio $R_{\mathrm{SR}}$ before and after turning time are calculated and listed in Table 2. It can be seen from Table 2 that data series were divided into 2 or 3 periods by the turning points at the four stations. Hydrological process in the first time period $D_{0}$ is usually a natural one due to less influence of human activities. The runoff and sediment transport in the following time periods $D_{1}$ and $D_{2}$ suffered from different degree of impact of reservoir operation; therefore, the changes in slope of cumulative runoff $R_{\mathrm{SR}}$ indicates the ratio of influence of human activities, especially reservoir operation, before and after the turning points. Between the first and second periods, the runoff decreased by $-24.45 \%,-8.20 \%$, and $-17.46 \%$ at the Baihe, Huangzhuang, and Xiantao stations, respectively.

As the runoff variation, also sediment load at the four stations shows extremely obvious changes before and after the turning points. Except for the natural time period $D_{0}$, cascaded reservoirs fundamentally changed the sediment transport in the following two time periods with the ratio of $-56.39 \%,-50.63 \%,-73.38 \%$, and $-57.96 \%$ at the Baihe, Huangjiagang, Huangzhuang, and Xiantao stations (Figure 10 and Table 3). Cascaded reservoirs have greatly changed fluvial processes in the Han River basin; therefore, the changed runoff process must have some influence on the sediment transport [38]. The extent of runoff variation impact on the sediment transport $C_{R}$ under reservoir operation before and after turning time is listed in Table 4 . It can be seen from
TABLE 2: Slope changes of runoff over time for different periods.

\begin{tabular}{lcccc}
\hline \multirow{2}{*}{ Stations } & \multirow{2}{*}{ Time periods } & \multirow{2}{*}{$S_{R} / 10^{8} \mathrm{~m}^{3} \mathrm{a}^{-1}$} & \multicolumn{2}{c}{$R_{\mathrm{SR}} / \%$} \\
Baihe & $D_{0}: 1955-1983$ & 253.81 & - & - \\
& $D_{1}: 1983-2012$ & 191.76 & -24.45 & - \\
\hline \multirow{3}{*}{ Huangjiagang } & $D_{0}: 1955-1958$ & 411.92 & - & - \\
& $D_{1}: 1958-1967$ & 419.6 & 1.86 & - \\
& $D_{2}: 1967-2013$ & 341.12 & - & -18.7 \\
\hline \multirow{3}{*}{ Huangzhuang } & $D_{0}: 1955-1967$ & 447.77 & - & - \\
& $D_{1}: 1967-1984$ & 411.07 & -8.20 & - \\
& $D_{2}: 1984-2013$ & 388.2 & - & -5.56 \\
\hline \multirow{3}{*}{ Xiantao } & $D_{0}: 1955-1965$ & 516.94 & - & - \\
& $D_{1}: 1965-1984$ & 426.7 & -17.46 & - \\
& $D_{2}: 1984-2012$ & 398.48 & - & -6.61 \\
\hline
\end{tabular}

Notes: $S_{R}$ is the slope of runoff accumulative curves before and after turning time; $R_{\mathrm{SR}}$ is the slope change ratio of cumulative runoff with time.

Table 4 that runoff variation under reservoir regulation has contributed a lot to the sediment transport, especially at the Baihe and Xiantao stations with the ratio of $43.35 \%$ and $30.12 \%$. In addition, although runoff variation has been playing an important role in the changes in sediment transport, other influencing factors also cannot be ignored [39]. For example, changes in flow discharge of river channels and 


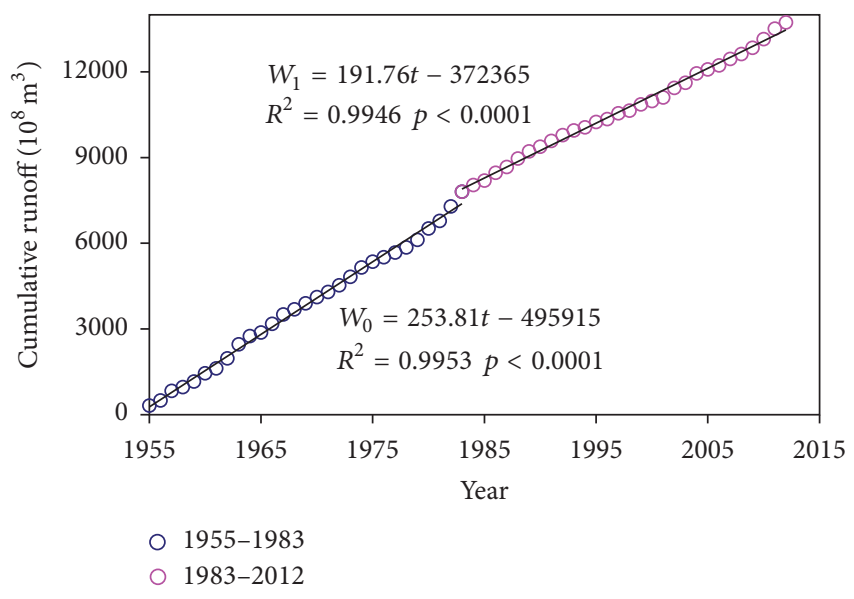

(a) Baihe

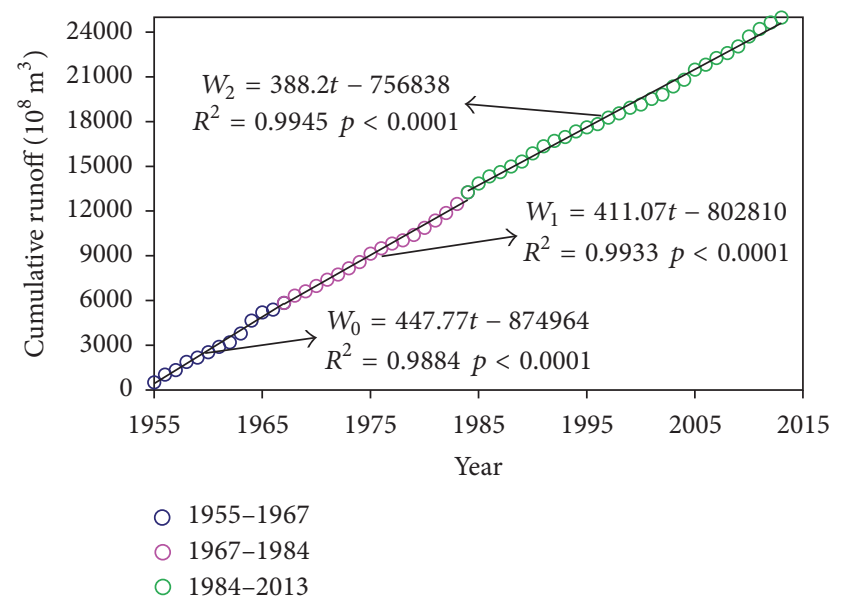

(c) Huangzhuang

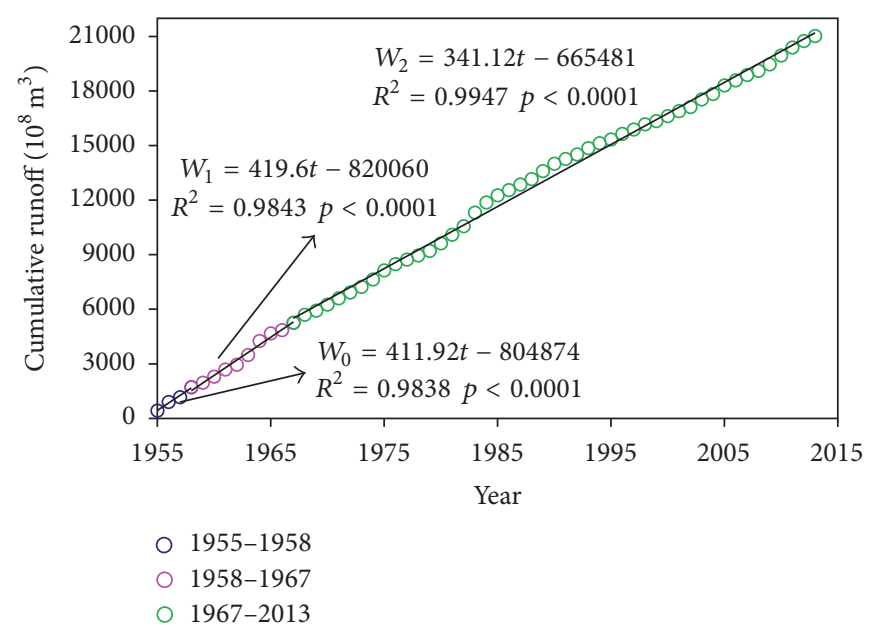

(b) Huangjiagang

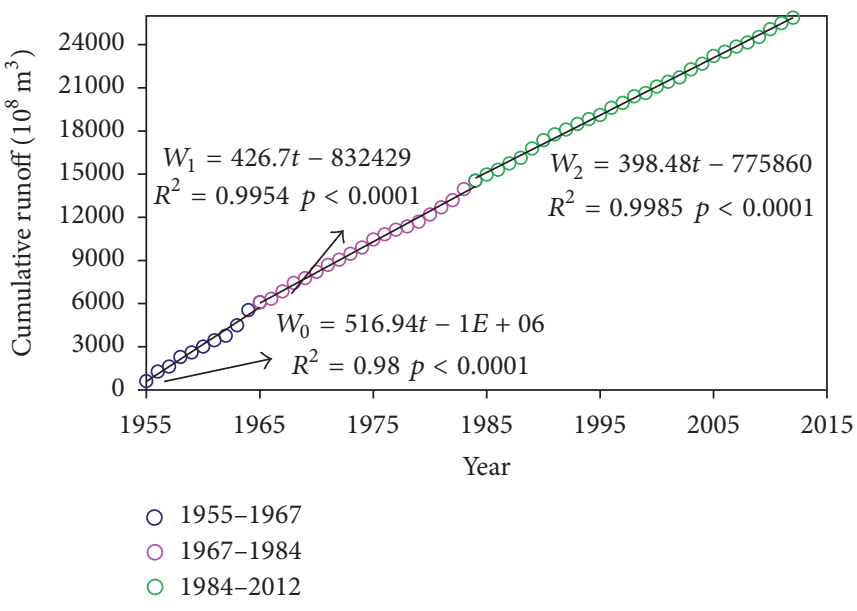

(d) Xiantao

FIgURE 9: Cumulative curves of runoff in different time periods.

TABLE 3: Slope changes of sediment load over time for different periods.

\begin{tabular}{lcccc}
\hline \multirow{2}{*}{ Stations } & \multirow{2}{*}{ Time periods } & \multirow{2}{*}{$S_{S} / 10^{8} \mathrm{~m}^{3} \mathrm{a}^{-1}$} & \multicolumn{2}{c}{$R_{\mathrm{SS}} / \%$} \\
Baihe & $D_{0}: 1955-1983$ & 0.4632 & - & - \\
& $D_{1}: 1983-2012$ & 0.202 & -56.39 & - \\
\hline \multirow{4}{*}{ Huangjiagang } & $D_{0}: 1955-1958$ & 1.5383 & - & - \\
& $D_{1}: 1958-1967$ & 0.7595 & -50.63 & - \\
& $D_{2}: 1967-2013$ & 0.0047 & - & -99.38 \\
\hline \multirow{4}{*}{ Huangzhuang } & $D_{0}: 1955-1967$ & 1.2132 & - & - \\
& $D_{1}: 1967-1984$ & 0.3229 & -73.38 & - \\
& $D_{2}: 1984-2013$ & 0.1082 & - & -66.49 \\
\hline \multirow{4}{*}{ Xiantao } & $D_{0}: 1955-1965$ & 0.7836 & - & - \\
& $D_{1}: 1965-1984$ & 0.3294 & -57.96 & - \\
& $D_{2}: 1984-2012$ & 0.1798 & - & -45.42 \\
\hline
\end{tabular}

Notes: $S_{S}$ is the slopes of sediment load accumulative curves before and after turning time; $R_{\mathrm{SS}}$ is the slope change ratio of cumulative runoff with time.
TABLE 4: Impacts of runoff variation on sediment transport in different periods.

\begin{tabular}{lcc}
\hline Stations & Time periods & $C_{R}(\%)$ \\
\hline \multirow{2}{*}{ Baihe } & $D_{0}: 1955-1983$ & - \\
& $D_{1}: 1983-2012$ & 43.35 \\
\hline \multirow{3}{*}{ Huangjiagang } & $D_{0}: 1955-1958$ & - \\
& $D_{1}: 1958-1967$ & -3.68 \\
& $D_{2}: 1967-2013$ & 18.82 \\
\hline \multirow{3}{*}{ Huangzhuang } & $D_{0}: 1955-1967$ & - \\
& $D_{1}: 1967-1984$ & 11.17 \\
& $D_{2}: 1984-2013$ & 8.37 \\
Xiantao & $D_{0}: 1955-1965$ & - \\
& $D_{1}: 1965-1984$ & 30.12 \\
& $D_{2}: 1984-2012$ & 14.56 \\
\hline
\end{tabular}

Notes: $C_{R}$ is the extent of runoff variation impact on the sediment transport before and after turning time. 


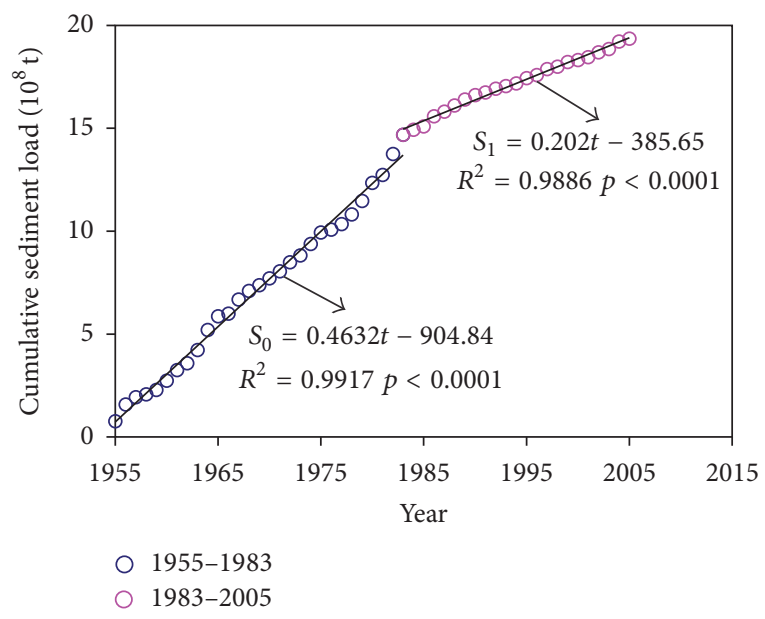

(a) Baihe

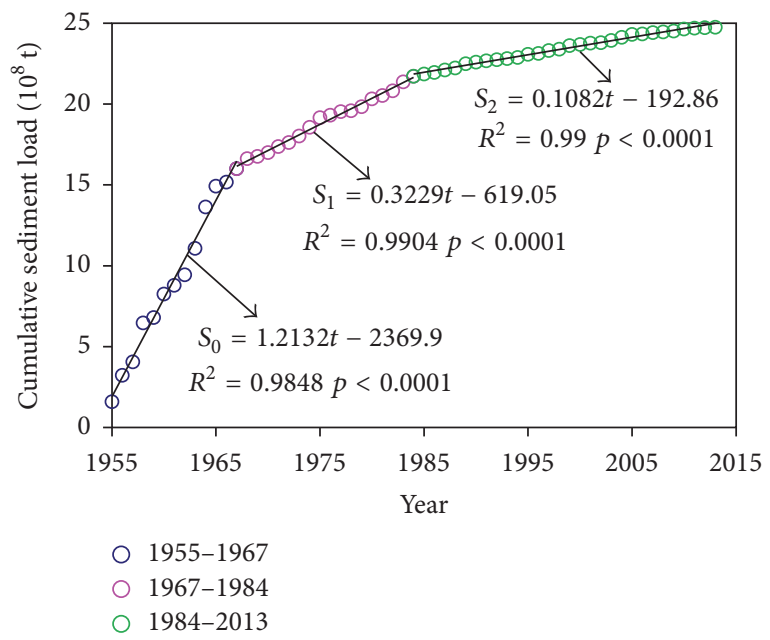

(c) Huangzhuang

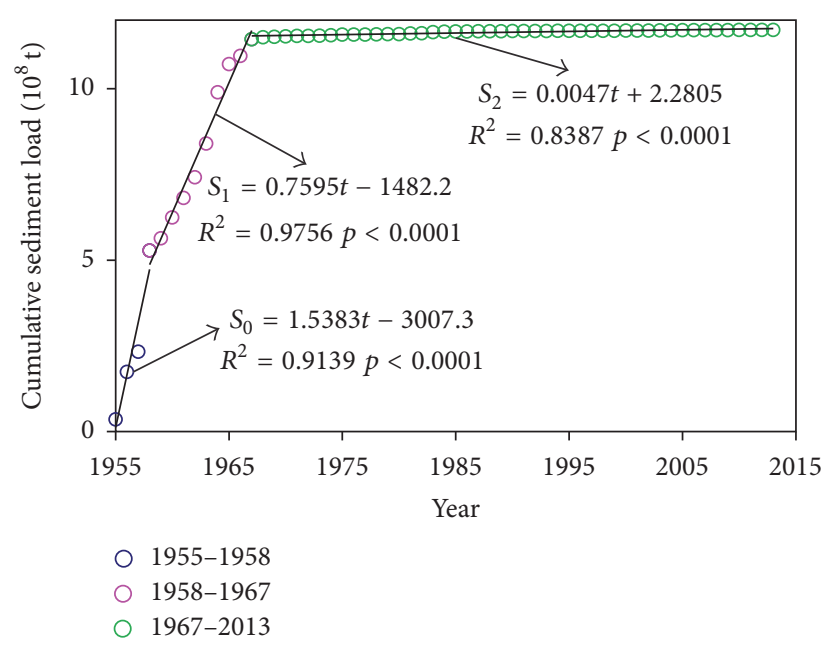

(b) Huangjiagang

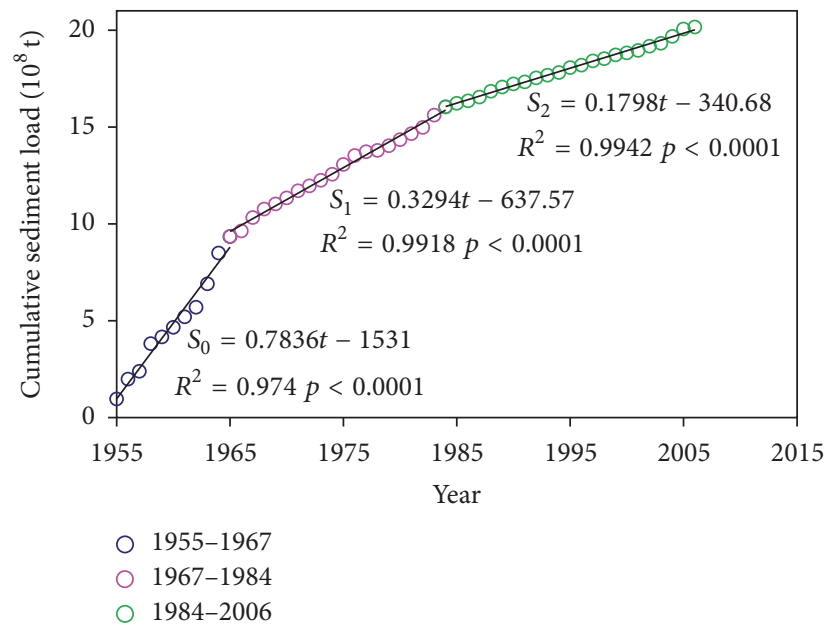

(d) Xiantao

FIGURE 10: Cumulative curves of sediment load in different time periods.

industrial and agricultural water consumption always play their indispensable roles in the sediment transport with the cascade hydropower exploitation of river basin [40].

\section{Conclusion}

With the rapid cascade hydropower exploitation in the Han River basin, runoff and sediment transport displayed great changes. In this study, we quantitatively evaluated the trends of hydrological process and identified the abrupt turning points of runoff and sediment load in the middle and lower Han River during the past 60 years. Some interesting and important conclusions were obtained as follows:

(1) Operation of cascade reservoirs has significantly influenced the hydrological process, and runoff and sediment load decreased in different degrees at the Baihe, Huangjiagang, Huangzhuang, and Xiantao stations. Compared with the sediment load, the change in runoff is not so large and shows time consistency.
The decreasing trend of sediment transport is very significant at the four stations because of reservoir operation during these periods.

(2) There are different turning points of runoff and sediment load at the Baihe, Huangjiagang, Huangzhuang, and Xiantao stations along the river. Abrupt changes occur at the four stations in 1983, (1858, 1967), (1967, 1984), and (1967, 1984), respectively. Although great changes in runoff and sediment load occur during different time periods, correlation still exists between runoff and sediment load before and after turning points.

(3) Runoff is always a driving factor for the changes in sediment transport, even under the operation of cascade reservoirs. The impact of runoff variation on sediment transport can be determined quantitatively based on the statistic $C_{R}$ defined in (8). Before and after the first turning point at the Baihe, Huangjiagang, Huangzhuang, and Xiantao stations, the $C_{R}$ values 
are $43.35 \%,-3.68 \%, 11.17 \%$, and $30.12 \%$, respectively, which means that the runoff variation has contributed a lot to the sediment transport, especially at the Huangjiagang and Xiantao stations.

\section{Competing Interests}

The authors declare that they have no competing interests.

\section{Acknowledgments}

This paper was financially supported by the CRSRI Open Research Program (Grant nos. CKWV2014205/KY, CKWV2015202/KY); the National Natural Science Foundation of China (51509273, 51679094, and 51409015); the Natural Science Foundation of Hubei Province, China (Grant no. 2015CFC872); Open Foundation of State Key Laboratory of Hydrology-Water Resources and Hydraulic Engineering (2015491111); the Open Research Fund of State Key Laboratory of Simulation and Regulation of Water Cycle in River Basin (China Institute of Water Resources and Hydropower Research), Grant no. IWHR-SKL-201607; the Technology Demonstration Projects of Ministry of Water Resources (SF2016-10); the Foundation of State Key Laboratory of Simulation and Regulation of Water Cycle in River Basin (2016TS07); the Research Development Projects on Application Technology of Heilongjiang Province (GZ16B011); and "the Fundamental Research Funds for the Central Universities", South-Central University for Nationalities (Grant nos. CZQ15007, CZW15072, and CZW15126).

\section{References}

[1] Z. Chen, J. Li, H. Shen, and W. Zhanghua, "Yangtze River of China: historical analysis of discharge variability and sediment flux," Geomorphology, vol. 41, no. 2, pp. 77-91, 2001.

[2] H. Thomas, "Effects of drought in the Colorado River Basin," Pro/Pap (372-F):50, U.S. Geological Survey, 1962.

[3] R. H. Meade and R. S. Parker, "Sediment in rivers of the United States," in National Water Summary, vol. 2275, pp. 49-60, U.S. Geological Survey Water-Supply Paper, 1985.

[4] Q. Zhang, C.-Y. Xu, V. P. Singh, and T. Yang, "Multiscale variability of sediment load and streamflow of the lower Yangtze River basin: possible causes and implications," Journal of Hydrology, vol. 368, no. 1-4, pp. 96-104, 2009.

[5] Z. Zhang, J. Huang, Y. Huang, and H. Hong, "Streamflow variability response to climate change and cascade dams development in a coastal China watershed," Estuarine, Coastal and Shelf Science, vol. 166, pp. 209-217, 2015.

[6] S. L. Yang, Z. Liu, S. B. Dai et al., "Temporal variations in water resources in the Yangtze River (Changjiang) over the Industrial Period based on reconstruction of missing monthly discharges," Water Resources Research, vol. 46, no. 10, pp. 1-13, 2010.

[7] Y. Li and R. R. Gu, "Modeling flow and sediment transport in a river system using an artificial neural network," Environmental Management, vol. 31, no. 1, pp. 122-134, 2003.

[8] P. Liu and Y. Li, "Analysis on flow and sediment changes at Jianli hydraologic station before and after impoundment of the Three Gorges reservior," Waterway \& Port, vol. 32, no. 6, pp. 408-412, 2011.
[9] M. Dai, L. Ye, and Y. Liu, "Study on encounter rules of floods from Han River and upper Yangtze River," Yangtze River, vol. 43, no. 1, pp. 48-51, 2012.

[10] J. Zhou, B. Lin, and R. Zhang, "A diversion canal for mitigating the floods in middle reach of Yangtze River and lower reach of Han River," Journal of Hydraulic Engineering, vol. 11, pp. 84-88, 2000.

[11] Q. Yang, P. Xie, H. Shen, J. Xu, P. Wang, and B. Zhang, "A novel flushing strategy for diatom bloom prevention in the lowermiddle Hanjiang River," Water Research, vol. 46, no. 8, pp. 25252534, 2012.

[12] Y. Guo, C. C. Huang, J. Pang et al., "Investigating extreme flood response to Holocene palaeoclimate in the Chinese monsoonal zone: a palaeoflood case study from the Hanjiang River," Geomorphology, vol. 238, pp. 187-197, 2015.

[13] H. He, Q. Zhang, J. Zhou, J. Fei, and X. Xie, "Coupling climate change with hydrological dynamic in Qinling Mountains, China," Climatic Change, vol. 94, no. 3-4, pp. 409-427, 2009.

[14] H. Chen, C.-Y. Xu, and S. Guo, "Comparison and evaluation of multiple GCMs, statistical downscaling and hydrological models in the study of climate change impacts on runoff," Journal of Hydrology, vol. 434-435, pp. 36-45, 2012.

[15] Changjiang Water Resources Commission (Ministry of Water Resources, China) (CWRC), Hydrological Records of the Yangtze River, Yangtze River Water and Sediment Bulletin, 2000 (Chinese).

[16] Changjiang Water Resources Commission (Ministry of Water Resources; China) (CWRC), Hydrological Records of the Yangtze River, Cyclopaedia Press of China, Beijing, China, 2000 (Chinese).

[17] M. Mourad and J.-L. Bertrand-Krajewski, "A method for automatic validation of long time series of data in urban hydrology," Water Science and Technology, vol. 45, no. 4-5, pp. 263-270, 2002.

[18] H. B. Mann, "Nonparametric tests against trend," Econometrica, vol. 13, pp. 245-259, 1945.

[19] M. G. Kendall, Rank Correlation Methods, Charles Griffin Book Series, Oxford University Press, London, UK, 1975.

[20] J. M. Mitchell, B. Dzerdzeevskii, H. Flohn et al., "Climate change," MO Technical Note 79, World Meteorological Organization, 1966.

[21] Q. Zhang, C.-Y. Xu, S. Becker, and T. Jiang, "Sediment and runoff changes in the Yangtze River basin during past 50 years," Journal of Hydrology, vol. 331, no. 3-4, pp. 511-523, 2006.

[22] S. Wang, M. Yan, Y. Yan, C. Shi, and L. He, "Contributions of climate change and human activities to the changes in runoff increment in different sections of the Yellow River," Quaternary International, vol. 282, pp. 66-77, 2012.

[23] S. Guo, J. Guo, J. Zhang, and H. Chen, "VIC distributed hydrological model to predict climate change impact in the Hanjiang basin," Science in China, Series E: Technological Sciences, vol. 52, no. 11, pp. 3234-3239, 2009.

[24] Y. Zhou and S. Guo, "Incorporating ecological requirement into multipurpose reservoir operating rule curves for adaptation to climate change," Journal of Hydrology, vol. 498, pp. 153-164, 2013.

[25] Y. Wang, D. Wang, and J. Wu, "Assessing the impact of Danjiangkou reservoir on ecohydrological conditions in Hanjiang river, China," Ecological Engineering, vol. 81, pp. 41-52, 2014.

[26] H. Zhang, P. Liu, X. Li, J. Zhou, and H. Chen, "Analysis of the change trend and cycle statistics of runoff in the upstream of 
Hanjiang River," Journal of Water Resources Research, vol. 3, no. 5, pp. 419-428, 2014.

[27] Y. He, F. Wetterhall, H. L. Cloke et al., "Tracking the uncertainty in flood alerts driven by grand ensemble weather predictions," Meteorological Applications, vol. 16, no. 1, pp. 91-101, 2009.

[28] X. Cheng, Y. Yang, M. Li, X. Dou, and Q. Zhang, "The impact of agricultural land use changes on soil organic carbon dynamics in the Danjiangkou Reservoir area of China," Plant and Soil, vol. 366, no. 1, pp. 415-424, 2013.

[29] M. Church, "Geomorphic response to river flow regulation: case studies and time- scales," River Research and Application, vol. 11, no. 1, pp. 3-22, 1995.

[30] X. Zha, C. Huang, J. Pang, J. Liu, and X. Xue, "Reconstructing the palaeoflood events from slackwater deposits in the upper reaches of Hanjiang River, China," Quaternary International, vol. 380-381, pp. 358-367, 2015.

[31] B. Chen and W. F. Krajewski, "Recession analysis across scales: the impact of both random and nonrandom spatial variability on aggregated hydrologic response," Journal of Hydrology, vol. 523, pp. 97-106, 2015.

[32] Q. Zhang, C. Liu, C.-Y. Xu, Y. Xu, and T. Jiang, "Observed trends of annual maximum water level and streamflow during past 130 years in the Yangtze River basin, China," Journal of Hydrology, vol. 324, no. 1-4, pp. 255-265, 2006.

[33] M. A. Casermeiro, J. A. Molina, M. T. De La Cruz Caravaca, J. Hernando Costa, M. I. Hernando Massanet, and P. S. Moreno, "Influence of scrubs on runoff and sediment loss in soils of Mediterranean climate," Catena, vol. 57, no. 1, pp. 91-107, 2004.

[34] X. Jiongxin, "Study of sedimentation zones in a large sand-bed braided river: an example from the Hanjiang River of China," Geomorphology, vol. 21, no. 2, pp. 153-165, 1997.

[35] C. Wu, Y. Wang, Q. Huang, J. Jin, and Y. Zhang, "Study on combined optimal operation of cascade hydropower stations based on accelerating genetic algorithm," Shuili Fadian Xuebao/Journal of Hydroelectric Engineering, vol. 30, no. 6, pp. 171177, 2011.

[36] J. K. Searcy and C. H. Hardison, Double-Mass Curves, Manual of Hydrology: Part 1. General Surface-Water Tecniques, United States Government Printing Offices, Washington, DC, USA, 1960.

[37] Z. Huo, S. Feng, S. Kang, W. Li, and S. Chen, "Effect of climate changes and water-related human activities on annual stream flows of the Shiyang river basin in arid north-west China," Hydrological Processes, vol. 22, no. 16, pp. 3155-3167, 2008.

[38] J. Xu, "Evolution of mid-channel bars in a braided river and complex response to reservoir construction: an example from the middle Hanjiang River, China," Earth Surface Processes and Landforms, vol. 22, no. 10, pp. 953-965, 1997.

[39] T. Lasanta, J. M. García-Ruiz, C. Pérez-Rontomé, and C. Sancho-Marcén, "Runoff and sediment yield in a semi-arid environment: the effect of land management after farmland abandonment," Catena, vol. 38, no. 4, pp. 265-278, 2000.

[40] X. Cai and M. W. Rosegrant, "Optional water development strategies for the Yellow River Basin: balancing agricultural and ecological water demands," Water Resources Research, vol. 40, no. 8, 2004. 


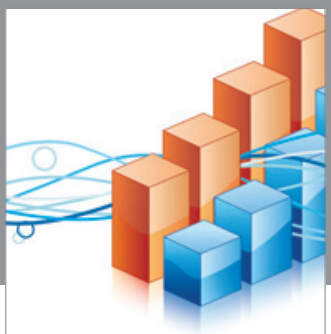

Advances in

Operations Research

vatem alat4

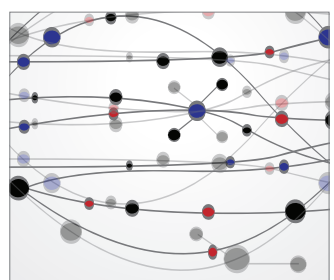

\section{The Scientific} World Journal
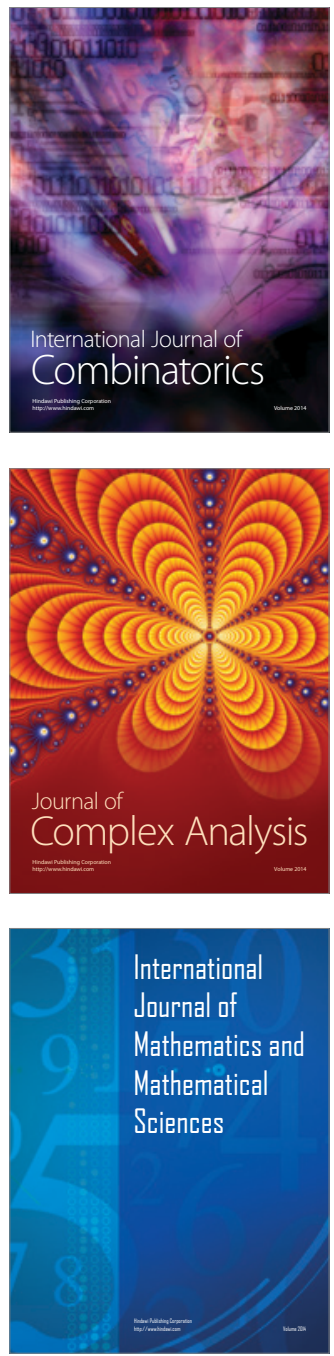
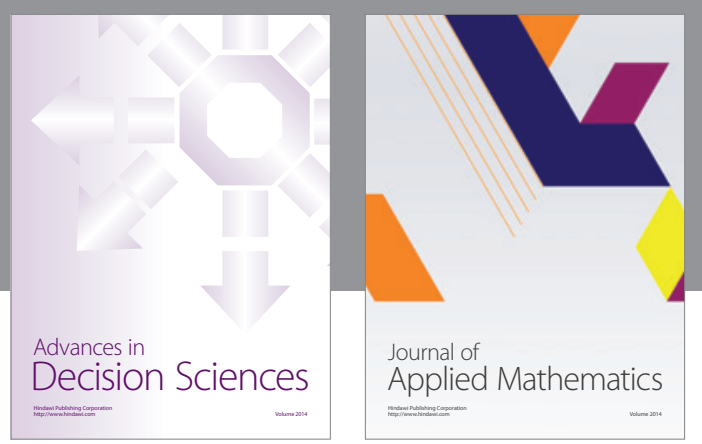

Algebra

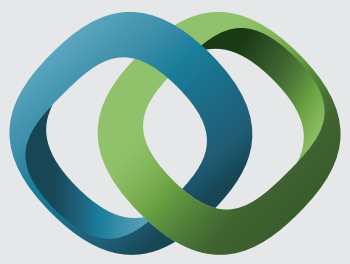

\section{Hindawi}

Submit your manuscripts at

https://www.hindawi.com
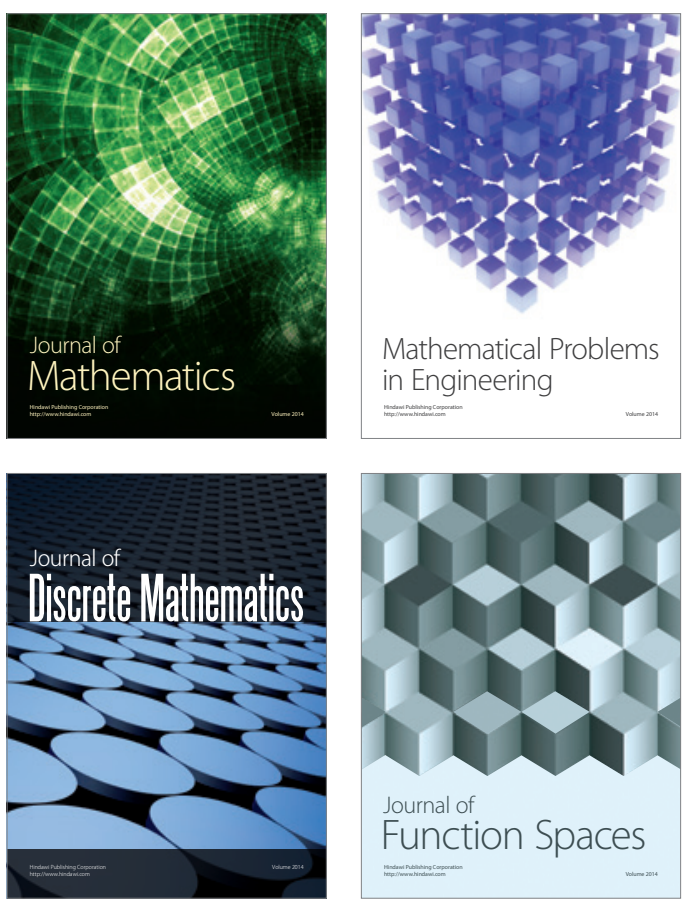

Mathematical Problems in Engineering
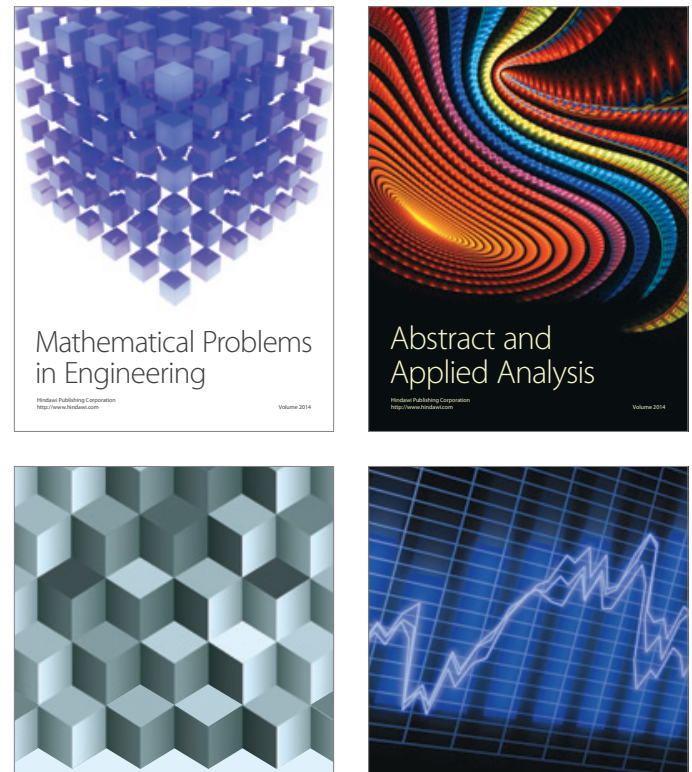

Journal of

Function Spaces

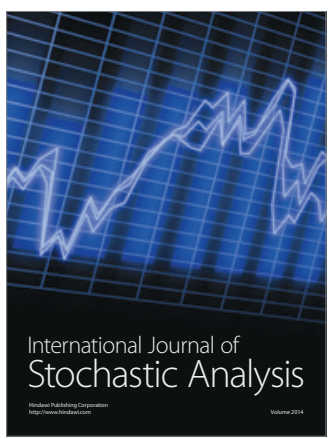

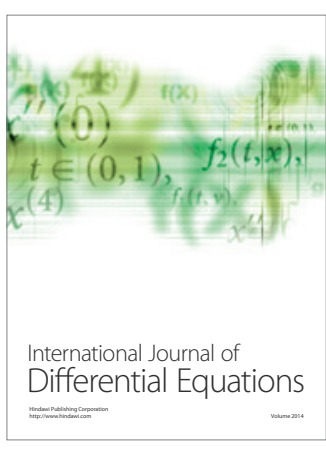
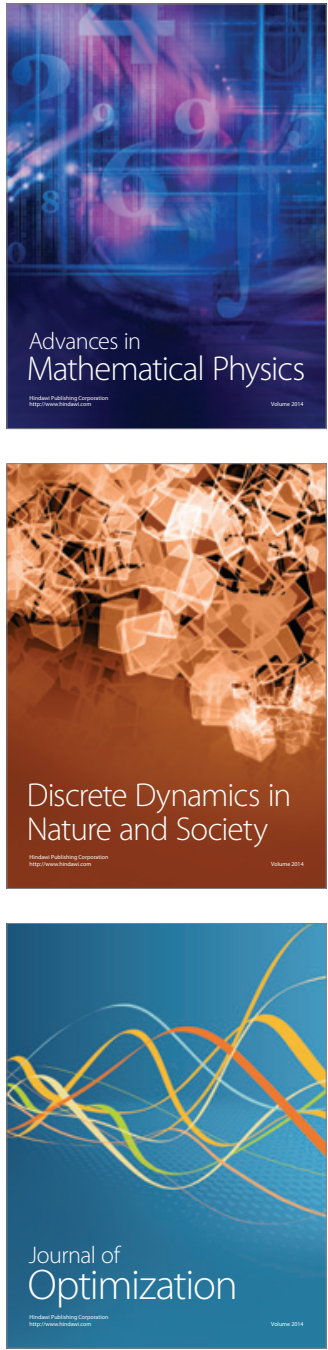